\title{
Iron-dependent mutualism between Chlorella sorokiniana and Ralstonia pickettii forms the basis for a sustainable bioremediation system
}

Deepak Rawat ${ }^{1,2}$, Udita Sharma ${ }^{1}$, Pankaj Poria ${ }^{1}$, Arran Finlan², Brenda Parker,*, Radhey Shyam Sharma ${ }^{1,3, *}$ Vandana Mishra ${ }^{1, *}$

Affiliations

1 Department of Environmental Studies, Bioresources \& Environmental Biotechnology Laboratory, University of Delhi, Delhi-110007, INDIA

2 Department of Biochemical Engineering, Bernard Katz Building, University College London, Gower Street, London WC1E 6BT, UK

3 Delhi School of Climate Change \& Sustainability, Institute of Eminence, University of Delhi, Delhi110007, INDIA

\section{Corresponding Authors (*)}

1. Prof. Vandana Mishra, Department of Environmental Studies, Bioresources \& Environmental Biotechnology Laboratory, University of Delhi, Delhi-110007, INDIA, +91 9871260287 , mistletoe_h@hotmail.com.

2. Dr Brenda Parker, Department of Biochemical Engineering, Bernard Katz Building, University College London, Gower Street, London WC1E 6BT, UK, 02076799789, brenda.parker@ucl.ac.uk.

3. Prof. Radhey Shyam Sharma, Department of Environmental Studies, Bioresources \& Environmental Biotechnology Laboratory, University of Delhi, Delhi-110007, INDIA, +91 98102 27222, radheyss26@gmail.com.

Keywords: Algae; Symbiosis; Algae-bacteria; Mutualism; Azo dye; Bioremediation; Azoreductase; Chlorella

Conflict of interest: All the authors unanimously declare lack of any competing financial and/or non-financial interests in relation to the work described in the MS. 


\begin{abstract}
Mutualism between microalgae and bacteria is ubiquitous, but remains underexplored as a basis for biodegradation of anthropogenic pollutants. In industrial systems, poor iron uptake by microalgae limits growth, bioprocessing efficacy, and bioremediation potential. Iron supplementation is costly and ineffective because iron remains insoluble in aqueous medium and biologically unavailable. In aquatic environments, microalgae develop an association with bacteria that solubilize iron by production of siderophore, which increases the bioavailability of iron as a public good. Algae, in exchange, provides dissolved organic matter to bacteria to sustain such interkingdom associations. Therefore, using a case study of azo dye degradation, we combine environmental isolations and synthetic ecology as a workflow, establishing a microbial community to degrade industrially relevant Acid Black 1 dye. We create a mutualism between previously non-associated chlorophyte alga Chlorella sorokiniana and siderophoreproducing bacterium Ralstonia pickettii, based on the eco-evolutionary principle of exchange of iron and carbon. This siderophore-mediated increased iron bioavailability increases reductive iron uptake, growth rate, and azoreductase-mediated dye degradation of microalga. In exchange, $C$. sorokiniana produces galactose, glucose, and mannose as major extracellular monosaccharides, supporting bacterial growth. We propose a mechanism whereby extracellular ferrireductase is crucial for azoreductase-mediated dye degradation in microalgae. Our work demonstrates that bioavailability of iron, which is often overlooked in industrial biodesigns, governs microalgal growth and enzymatic processes. Our results suggest that algalbacterial consortia based on the active association are a self-sustainable mechanism to overcome existing challenges of micronutrient availability in bioremediation systems and their industrial translation.
\end{abstract}




\section{Introduction}

Microalgae have potential in the creation of a circular economy, preventing pollution, and enabling the reuse of water as a resource. The textile industry releases $\sim 5$ million tons of untreated wastewater annually into waterways, accounting for $1 / 5^{\text {th }}$ of the global water pollution and releasing ecotoxic compounds like aromatic amines arising from incomplete degradation of dye by environmental microbes [1]. Exposure to dye contaminants arising from textile industries disproportionately affects emerging economies like China, India, and Bangladesh, hubs of textile dyeing, where environmental regulations are relaxed, and wastewater treatment and management are inefficient [2,3]. Therefore, there is an urgent need to address the sustainability of this sector.

Commonly used physico-chemical methods aim for only color removal and recently employed zero-liquid discharge techniques convert liquid waste into untreatable hazardous sludge [4]. Though alternative biological methods can be advantageous for industrial use in developing countries, they have lower operational costs, generate less sludge, and result in degradation of dye toxicants into environmentally benign compounds [5], yet their potential remains unrealized, owing to constraints related to biomass upscaling under unfavorable environmental conditions of wastewater and integration in the current infrastructure.

Microalgae such as Chlamydomonas, Chlorella, Dunaliella, Micratinium, Scenedesmus, and Phaeodactylum have been investigated for their use in wastewater treatment and in biorefinery processes to recover valuable products of interest [6-11]. In particular, species of Chlorella and Scenedesmus have received attention for wastewater applications, including textile, due to their rapid doubling times and tolerance for a wide range of nutrient conditions [8, $12,13]$. However, in industrial wastewater, algal processes may be challenged by extrinsic constraints of micronutrient availability and intrinsic constraints of micronutrient utilization. The inability of algae to take up complexed iron limits its efficacy to treat industrial wastewater [14], which has low iron concentrations and even low bioavailability due to high alkalinity ( $\mathrm{pH}$ 8.5-10) $[15,16]$. Microalgae require $\mathrm{Fe}^{2+}$ for photosynthesis, respiration, nitrogen-fixation, uptake of nutrients, and metabolism of reactive oxygen species [17]. Although abundant in the environment, iron remains unavailable to algae due to its presence as insoluble ferric $\left(\mathrm{Fe}^{3+}\right)$ or oxyhydroxides or as bound to minerals and organics. In alkaline conditions, like in wastewater from the textile industry, iron precipitates out or dissolute slowly [16, 18]. Therefore, bioavailable 
iron remains an insignificant fraction in aqueous environments, thus, acts as a major limiting factor for upscaling of microalgal-based processing of wastewater treatment.

Phototrophs and heterotrophs occupy distinct ecological niches but may engage in mutualism to complement their physiological capabilities and metabolic versatilities to enhance fitness [19-23]. Photoautotrophic microalgae represent a source of dissolved organic carbon that may be supplied to heterotrophic bacteria. In contrast to microalgae, many species of heterotrophic bacteria produce siderophores, low molecular weight iron chelators, as a part of the highly efficient iron-uptake mechanism in iron-stressed environments [21]. To overcome their physiological limitations, autotrophic algae exchange dissolved organic matter with heterotrophic bacteria in lieu of non-bioavailable micronutrients and other metabolites [24, 25].

In bioremediation designs and bioprocesses, single-species cultures have several physiological limitations that challenge their use in industrial wastewater treatment [26]. For example, microalgal monocultures are challenged with limited bioavailability of micronutrients (like Fe, Mn, vitamins), the metabolic burden of maintaining essential cellular processes under stressful conditions [27, 28]. In textile wastewater remediation, bacterial monocultures are challenged by the sensitivity of azoreductase enzymes for oxygen [29], necessitating a complex two-stage approach for complete dye removal. They require an oxygen-limiting environment to reduce azo dyes to aromatic amines extracellularly. Further treatment requires a well-oxygenated environment for oxidative degradation of aromatic amines [4]. Photosynthetic algae have been reported to degrade dye [13]; however, azoreductases in microalgae have not been studied previously. Unlike bacteria, microalgae could regulate external oxygen concentrations, therefore, could provide a simpler single-stage solution for complete azo dye degradation [12]. Also, algalmediate oxygen release in wastewater facilitates bacterial growth in primary treatment processes and accelerates the degradation of organic pollutants [30], which will complement the degradation of aromatic amines in dye wastewater.

Therefore, employing mutualistic microalgae and bacteria would ensure their use as a sustainable option in remediating toxicants and combating environmental stresses by distributing tasks to share the metabolic burden [31]. In freshwater and marine ecosystems, siderophoreproducing bacteria develop a mutualistic association with other microbes, including microalgae, therefore, govern the structure and function of microbial communities [25, 32]. In alkaline conditions, found in textile wastewater, bacterial siderophores, due to chelation and higher 
dissolution, could enrich iron in the immediate environment to use as public goods [16, 33]. This ensures higher primary productivity of microalgae for a continued exchange of dissolved organic matter. However, the impact of such eco-evolutionary principles of mutualism between organisms in improving the sustainability of bioremediation processes is largely underexplored $[26,34,35]$.

Therefore, the present study was aimed to (i) assess the role of siderophore-producer bacteria in enhancing the growth of microalgae under iron-limiting conditions and (ii) to assess the potential of the microalgal-bacterial consortium in degrading azo dyes. We isolated siderophore-producer Ralstonia pickettii from industrial wastewater and demonstrated their ability to undergo mutualistic association with previously non-associated freshwater microalgae Chlorella sorokiniana, and assessed the efficacy of mutualism-assisted azoreductase-mediated microalgal remediation of textile dyes.

\section{Results and discussion}

\section{Assessment of siderophore production in bacteria and dye degradation in algae}

Out of seven bacterial isolates purified from the untreated textile wastewater, five isolates showed relatively high siderophore production (Supplementary Fig. S1). Ralstonia pickettii PW2, Serratia plymuthica PW1, and S. liquefaciens PW71 grew within 24 h on deferrated CAS agar plates and showed siderophore activity, i.e., the appearance of the orange-yellow zone due to siderophore-mediated removal of Fe from blue-colored CAS-HDTMA-Fe complex [40]. Stenotrophomonas maltophilia PW5 and S. maltophilia PW6 showed high growth and siderophore production but only after 96 h of incubation. S. rhizophila PW3 and S. rhizophila PW72, however, failed to grow on CAS agar plates. S. plymuthica PW1, S. liquefaciens PW71, and $R$. pickettii $\mathrm{PW} 2$ produced siderophore in decreasing order of concentration, i.e., $15.26 \pm 1.3$ $>13.28 \pm 0.9>10.85 \pm 0.7 \mu \mathrm{MmL}^{-1}$ (Table 1). Arnow's and Csaky's assay confirmed a catecholate-type siderophore is produced by Serratia plymuthica PW1 $\left(81.10 \pm 9.8 \mu \mathrm{MmL}^{-1}\right)$, Ralstonia pickettii PW2 $\left(97.43 \pm 16.8 \mu \mathrm{MmL}^{-1}\right)$, and Serratia liquefaciens PW71 (103.1 \pm 8.3 $\left.\mu \mathrm{MmL}^{-1}\right)$. On the other hand, hydroxamate-type of siderophore is produced by S. maltophilia PW5 (37.86 $\left.\pm 0.4 \mu \mathrm{MmL}^{-1}\right)$ and $S$. maltophilia PW6 (17.73 $\pm 0.2 \mu \mathrm{MmL}^{-1}$ ) (Table 1). As $S$. 
rhizophila PW3 and S. rhizophila PW72 showed low culturability in iron-limiting conditions, they were omitted from further experiments.

Our study also reports S. plymuthica PW1 and S. liquefaciens PW71 from textile dye effluent produce catecholate siderophores (Table 1), which is common among stress-tolerant bacterial genera [51]. Different Serratia species thrive well in contaminated environments such as textile dye effluent and petroleum [52]. R. pickettii PW2, a $\beta$-proteobacterium, has also been reported to produce siderophores under iron stress[53].

Out of the five algal species screened, the two freshwater microalgae C. sorokiniana, Scenedesmus sp., and the freshwater cyanobacterium $O$. animalis were observed to degrade $\mathrm{AB} 1$ dye. After $72 \mathrm{~h}$, the AB1 degradation potential of microalgae was in decreasing order as $C$. sorokiniana $(82.10 \pm 1.6 \%)>$ Scenedesmus sp. $(31.04 \pm 3.1 \%)>$ O. animalis $(30.36 \pm 1.8 \%)$. The marine algal species Phaeodactylum tricornutum 1052/6 and 1055/1 did not decolorize AB1 dye under the conditions tested. Chlorella and Scenedesmus sp. have also been known to degrade a wide range of pollutants such as textile dyes [12, 54], heavy metals [21], pesticides [6], and aromatic hydrocarbons [54]. Therefore, we selected Chlorella and Scenedesmus for testing and developing an algal-bacterial consortium for dye degradation.

\section{Iron and carbon dependent mutualism between Chlorella sorokiniana and Ralstonia pickettii}

The exudates from $C$. sorokiniana and Scenedesmus sp. were used as a source of dissolved organic matter for cultivating bacteria and identifying microalgal-bacterial combination having the potential to act as a consortium (Fig. 1E). All five bacterial isolates grow well on filtersterilized exudate of $C$. sorokiniana as a sole source of carbon. On the contrary, on exudate of Scenedesmus sp., S. plymuthica PW1 showed moderate growth in $20 \mathrm{~h}$ while the growth of $R$. pickettii PW2 and S. liquefaciens PW71 remained insignificant. S. maltophilia PW5 and S. maltophilia PW6 did not grow on the exudate of Scenedesmus sp. (Supplementary Fig. S2B).

Different combinations of consortia with microalgal (C. sorokiniana / Scenedesmus $\mathrm{sp}$.) and siderophore-producer bacterial (S. plymuthica PW1/ R. pickettii PW2/ S. liquefaciens PW71) partner were assessed for dye degradation under iron limitation (Fig. 1F). Microalgal cell count in consortium culture was compared with that of axenic microalgal culture to categorize its interaction 
with a bacterial partner as mutualistic, antagonistic, and neutral. In contrast with axenic microalgal culture $\left(\sim 4 \times 10^{6}\right.$ cells $\left.\mathrm{mL}^{-1}\right), C$. sorokiniana in co-culture with $R$. pickettii $\mathrm{PW} 2$ showed a significant increase in cell count at $200 \mathrm{~h}\left(\sim 6 \times 10^{6}\right.$ cells $\left.\mathrm{mL}^{-1}\right)$, suggesting a mutualistic association (Fig. 2A). However, S. plymuthica PW1 exerted an antagonistic effect on the growth of $C$. sorokiniana, whereas, the interaction between S. liquefaciens PW71 and C. sorokiniana remained neutral (Fig. 2A). During early growth, the interaction between Scenedesmus sp. and S. plymuthica PW1 remained neutral; however, later, the interaction turned as antagonistic (Fig. 2A). Whereas the interaction of Scenedesmus sp. with both $R$. pickettii PW2 and S. liquefaciens PW71 was neutral. Scenedesmus showed a higher growth $\left(\sim 12 \times 10^{6}\right.$ cells $\left.\mathrm{mL}^{-1}\right)$ than axenically grown Chlorella $\left(\sim 5 \times 10^{6}\right.$ cells $\left.\mathrm{mL}^{-1}\right)$, suggesting an effective iron-uptake mechanism under iron-limiting conditions.

Growth parameters such as carrying capacity (k), intrinsic growth rate (r), doubling time (Dt), and area under the curve (auc) provided better insights into the population ecology of microalgae [42] (Supplementary Fig. S2, Table S1, and Table S2). As indicated by a steeper slope of log-phase in the growth curve (Fig. 3A), the growth rate (r) of C. sorokiniana in consortium with $R$. pickettii PW2 $\left(5.02 \pm 1.0 \times 10^{-2} \mathrm{~h}^{-1}\right)$ remained significantly higher than that of axenically grown microalgae $\left(1.95 \pm 0.3 \times 10^{-2} \mathrm{~h}^{-1}\right)(p=0.000)$. However, the carrying capacity $(\mathrm{k})$ of $C$. sorokiniana remains unchanged with and without culturing with $R$. pickettii PW2 (coculture: $4.97 \pm 0.1 \times 10^{6}$ cells vs axenic culture: $4.82 \pm 0.4 \times 10^{6}$ cells; $p=1.000$ ). In the consortium, C. sorokiniana showed a higher population turnover during the early log-phase and reached the stationary phase earlier (at $100 \mathrm{~h}$ ) than that grown axenically ( 270 h) though carrying capacity (k) remained similar. A significantly higher area under curve (auc) in the consortium $\left(11.01 \pm 0.4 \times 10^{8}\right)$ of $R$. pickettii PW2 in comparison with its axenic culture $\left(6.01 \pm 0.5 \times 10^{8}\right)$ ( $p=0.000)$ indicate mutualism between $C$. sorokiniana and $R$. pickettii PW2 (Fig. 3A).

S. plymuthica PW1 exerted an antagonistic effect on $C$. sorokiniana as indicated by its significant increase in its doubling time (Dt) $(p=0.009)$ with lower growth rate (r), carrying capacity (k), and area under curve (auc), comparing with the axenic culture of microalga (Fig. 3A). However, the lack of significant difference in growth parameters of $C$. sorokiniana co-cultured with S. liquefaciens PW71 indicates a neutral relationship between the two (Supplementary Table S2). S. plymuthica PW1, S. liquefaciens PW71 and R. pickettii PW2 showed an antagonistic effect on Scenedesmus sp., though the degree of effect varied (Fig. 3A). Co-culture of S. plymuthica PW1 with Scenedesmus sp., for example, caused a significantly reduced carrying capacity 
$(p=0.000)$ and area under curve $(p=0.003)$ of Scenedesmus sp. (Supplementary Table S2). Among these bacteria, S. plymuthica PW1 was antagonistic to both the microalgae.

Biplot based on principal component analyses (PCA) of microalga growth parameters in different experimental setups explained the mutualistic, antagonistic, and neutral effect of siderophore-producer bacteria on the growth of $C$. sorokiniana and Scenedesmus sp. (Fig. 3B). In PCA bioplot, $C$. sorokiniana (CS) grown axenically and in consortium with $R$. pickettii PW2 (CSPW2) formed separate groups based on the growth rate (r). Increasing growth rate (r) of microalgae with the consortium in iron-limiting condition confirms the benefits to microalgae due to iron made bioavailable by a siderophore-producing bacterium [55]. Bioavailable iron continues to accelerate microalgal growth until the iron exhausts at the stationary phase (Supplementary Fig. S2B). Such an iron-dependent mutualistic interaction between previously non-associated algae and bacteria has been shown between Dunaliella bardawil and Halomonas sp., where Halomonas sp. facilitates the iron in exchange for microalgal DOM [41]. In a marine environment, the vibrioferrin siderophore produced by Marinobacter sp. accelerates Scrippsiella trochoidea growth [19]. Similarly, Idiomarina loihiensis RS14 siderophore promotes the growth of freshwater alga Chlorella variabilis [56]. On the contrary, C. sorokiniana grown in co-culture with S. plymuthica PW1 (CSPW1) and as an axenic alga (CS) separated on the biplot due to distinct 'doubling time (Dt)', which is also supported by the slower growth in consortium due to antagonism by a bacterial partner as observed from algal growth curve (Fig. 2A).

Scenedesmus had a faster doubling time than Chlorella, therefore, grouped along with area under curve (auc) and carrying capacity (k) in the PCA biplot (Fig. 3B). In PCA biplot, Scenedesmus sp. from three setups, i.e., axenically grown (SS), co-cultured with $R$. pickettii PW2 (SSPW2), and S. liquefaciens PW71 (SSPW71) were grouped along with the growth variables, carrying capacity $(\mathrm{k})$ and area under curve (auc) metric. As 'auc' metric explains $54.7 \%$ of variations in the grouping, it represents the dominant variable or Principal Component 1 (PC1) (Fig. 3B). Thus, the presence of bacterial strains R. pickettii PW2 and S. liquefaciens PW71 showed neutral interactions with Scenedesmus sp. as also observed from algal growth curves (Fig. 2A). Scenedesmus, however, was affected by co-culturing with S. plymuthica PW1 (SSPW1) in comparison to axenic growth (SS), as both were plotted separately due to reduced algal growth in the consortium (Figs. 2B, 3B). On the other hand, the growth rate (r) forms the PC2, which explains $37.7 \%$ of the variations in the grouping and explains the faster growth of $C$. 
Sorokiniana in consortium with siderophore-producing $R$. pickettii PW2 under iron-limiting conditions.

The HPAEC analyses of exopolysaccharides (EPS) of C. sorokiniana detected galactose $\left(0.03 \pm 0.0 \mathrm{gL}^{-1} \mathrm{gcell}^{-1} ; 52 \%\right)$ as a dominant monosaccharide besides glucose $\left(0.01 \pm 0.0 \mathrm{gL}^{-1} \mathrm{gcell}^{-}\right.$ $\left.{ }^{1}, 20 \%\right)$, mannose $\left(0.01 \pm 0.0 \mathrm{gL}^{-1} \mathrm{gcell}^{-1} ; 20 \%\right)$, arabinose (4\%), and rhamnose (4\%) (Fig. 2C and Supplementary Fig. S3A). S. plymuthica PW1 grew well in all five monosaccharides $(0.1 \%)$, being galactose as the most preferred carbon source (Fig. 2D). R. pickettii PW2 showed a preference for galactose followed by glucose and mannose, though the growth promoted was relatively lower than that observed in S. plymuthica PW1. Sugar composition in microalgal EPS, governs microalgal-bacterial interaction [57]. In C. sorokiniana, galactose has been previously reported as a dominant monosaccharide (67\%). Galactose also serves as a signaling molecule in bacteria, and its presence in EPS has been hypothesized to extend stationary phase in microalga Botryococcus braunii [58]. In contrast with Chlorella, Scenedesmus sp. showed a different sugar profile with glucose (37\%), mannose (32\%), and rhamnose (12\%) as major monosaccharides (Fig. 2A). Bacteria grew well on Chlorella exudates rich in galactose than the exudates of Scenedesmus sp. rich in glucose and mannose (Supplementary Fig. S2B), suggesting the sugar profile of EPS govern the microalgal-bacterial association.

EPS-associated mono- and oligo-saccharides act as chemotactic molecules in microalgae to attract bacteria rather than serving as a source of carbon for bacterial growth [59]. Bacteria secreting exoenzymes hydrolyzing high molecular weight polysaccharides for continued carbon can sustain such associations. $R$. pickettii PW2 showed high growth in co-culturing with $C$. sorokiniana, suggesting its EPS preference (Fig. 2B). Though the commensal association between $C$. sorokiniana and bacteria with a high percentage identity to $R$. pickettii has been shown under nutrient-sufficient photoautotrophic conditions [60], our study suggests Chlorella EPS serves both as a source of DOM and chemotactic molecule, which governs the mutualistic association between them under the iron limitation. Furthermore, quorum sensing in microbes regulates the dynamic social behavior of bacteria and algae in the presence of 'public goods' like sugars and siderophore-chelated iron, a subject of the previous investigations [61]. Metagenomics also shows co-occurrence of $R$. pickettii with microalgae Botryococcus braunii [62], suggesting a wider environmental co-existence of the bacteria with microalga found in fresh and brackish waters. 
Under experimental conditions, S. plymuthica PW1 showed $~ 10$ times more growth than R. pickettii PW2 when co-cultured with C. sorokiniana (Fig. 2B). Antagonism between $S$. plymuthica PW1 and C. sorokiniana could be attributed to its aggressive growth (Fig. 2A). Also, S. plymuthica PW1 grew in all five sugars, suggesting a generalist and competitive life strategy (Fig. 2D). Serratia is also known to secrete serine protease, which lyses algal cells, providing a competitive advantage [63].

\section{Bioavailable iron influences dye degradation by Chlorella sorokiniana}

To ascertain the significance of biologically available iron from bacterial siderophore, the dye degradation potential of $C$. sorokiniana was analyzed in axenic and consortium culture in irondeficient and -sufficient conditions. EDTA-chelated iron increased dye decolorization potential of $C$. sorokiniana after $24 \mathrm{~h}$ (Fig. 4A). In treatment setups without EDTA-chelated iron, coculture of microalga and bacteria significantly reduces half-life of $\mathrm{AB} 1$ dye compared to the axenic algal setup $(p=0.000$; consortium: half-life $=65.40 \pm 0.5 \mathrm{~h}$; axenic algal: half-life $=$ $120 \pm 9.4 \mathrm{~h}$ ) (Supplementary Table S3 and Table S4). However, in the setups with EDTAchelated iron, the half-life of $\mathrm{AB} 1$ lacks any significant difference between the experimental setup with the consortium and axenic algae ( $p=0.806$; consortium: half-life $=15.27 \pm 2.5 \mathrm{~h}$; axenic algal: half-life $=21.59 \pm 1.9$ h) (Fig. 4 A). In an experimental setup without EDTAchelated iron, the dye degradation follows Simple First Order (SFO) kinetics [64]. In contrast, with EDTA-chelated iron, the degradation follows a First Order Multi-Compartment (FOMC) (Fig. 4A and Supplementary Fig. S4). FOMC represents a biphasic degradation indicating an initial steep decline in dye concentration followed by a relatively slower degradation. Coculturing of siderophore-producer $R$. pickettii PW2 and C. sorokiniana significantly increased dye degradation by microalga only in the absence of EDTA-chelated iron (Fig. 4A). Bacteria produce siderophore in low iron conditions [65]; however, EDTA being a strong chelator, significantly increases available iron (Fig. 4A and Supplementary Table S4). Bacterial presence, therefore, lacks any significant effect on algal dye degradation due to the high bioavailability of iron ( $p=0.807$ ) (Fig. 4A and Supplementary Table S4). Thus, R. pickettii PW2 increases the dye degradation potential of $C$. sorokiniana only under iron-limiting conditions. In contrast, axenic bacteria lack detectable dye degradation suggesting a significant contribution of a microalgal partner in dye degradation in the consortium. 
To determine the role of biotic and abiotic factors in dye degradation, the factors relevant to industrial wastewater were chosen in designing 32 experiments with two setups, i.e., axenic microalgal culture and microalgal-bacterial consortium (Supplementary Fig. S5 and Table S5). Using $\mathrm{L}_{16}\left(4^{3}\right)$ orthogonal array design, the dye degradation rate was calculated. $\mathrm{L}_{16}$ $\left(4^{3}\right)$ design was used to test varying $\mathrm{Fe}^{3+}$ and dye concentration and $\mathrm{pH}$ level. The $\mathrm{Fe}^{3+}$ concentration was kept lower or higher than $1 \times 10^{-6} \mathrm{M}$, a concentration known to induce ironstarvation due to variation in the equilibrium between intra- and extracellular Fe concentration, thus necessitating bacterial siderophore production $[33,66] . \mathrm{pH}$ determines the iron solubility and growth of microbes [67], whereas the concentration of AB1 dye (substrate) affects the enzymatic activity and the rate of dye degradation.

Multiple regression suggests the $\mathrm{Fe}^{3+}$ concentration (delta value; axenic algal $=0.02$, consortium $=0.03$ ) as a primary factor governing the rate of dye degradation followed by the azo dye concentration (delta value; axenic algal $=0.01$, consortium $=0.02$ ) (Fig. $4 \mathrm{~B}$, Supplementary Table S6 and Table S7). The delta value in Taguchi's orthogonal design takes all the factors individually to determine the difference between the highest and lowest value of the average response variable. Therefore, a higher delta value of a particular factor represents a significant effect of variation in the level of the factor. Changing the concentration of $\mathrm{Fe}^{3+}$ led to a considerable variation in the rate of $\mathrm{AB} 1$ degradation in both axenic algal $(p=0.001)$ and consortium ( $p=0.002$ ) setups (Fig. 4B). In both the experimental setups, the rate of AB1 degradation was inversely proportional to the concentration of $\mathrm{Fe}$ (Fig. 4B). Consortium showed an enhanced average rate of $\mathrm{AB} 1$ degradation $\left(0.04 \mathrm{~h}^{-1}\right)$ as compared with axenic cultures $\left(0.03 \mathrm{~h}^{-1}\right)$ (Fig. 4B). Siderophore-producer bacteria increase dye degradation potential of microalga at $1 \times 10^{-7}$ and $1 \times 10^{-6} \mathrm{M} \mathrm{Fe}$, whereas at a higher $\mathrm{Fe}^{3+}$ concentration, the bacterial effect remains neutral.

The dye concentration shows an inverse relationship with the rate of dye degradation in both axenic algal $(p=0.028)$ and consortium $(p=0.008)$ setups; however, it reached up to $60 \%$ even at high dye concentrations (Fig. 4B and Supplementary Table S5). At a high concentration, the dye molecules compete for electrons generated by the azoreductasemediated enzymatic pathway at the microbial membrane [68], reducing dye degradation rate. Similarly, the siderophore-producer bacteria increased the rate of dye degradation at low dye concentrations only (Fig. 4B, Supplementary Table S6 and Table S7). Dye degradation in microbes is a non-growth associated extracellular process driven by plasma membrane-bound 
azoreductase, a non-specific oxidoreductase [48]. Azoreductase facilitates the transfer of electrons from microbial cells to electron-deficient azo bond $(-\mathrm{N}=\mathrm{N}-)$, which reduces azo dyes into colorless aromatic amines via a two-cycle transfer of electrons following a ping-pong bibi mechanism $[29,68]$. Azoreductase is engaged in oxidoreductase reaction with extracellular intermediates such as redox mediators like flavins which transfer electrons from within the microbial cell to extracellular azo bond. Therefore, the optimal ratio between the microalgal cells and dye molecules has a significant influence on catalytic efficiency and turnover number of enzymes for azo dye degradation. Contrary to this, the difference in the rate of $A B 1$ degradation at varying $\mathrm{pH}$ was not significant $(p>0.1)$ in both consortium and axenic algal setups (delta value; axenic algal $=0.01$, consortium $=0.01)($ Supplementary Table S6). Thus, as per the $\mathrm{L}_{16}$ orthogonal design, the variation in $\mathrm{pH}$ has a little effect on dye degradation potential by microalgae $C$. sorokiniana (Fig. 4B).

UPLC, FTIR, and LC-MS analysis confirm AB1 degradation by the microalgal-bacterial consortium (Fig. 5A). In chromatogram, the peak at retention time (RT) 2.617 corresponding to AB1 dye disappeared. The new peaks at RT 0.674, 0.944, and 1.944 appeared, which confirms the formation of less polar products on azo dye degradation. In the FTIR analysis, the disappearance of vibrational bands at $1,488 \mathrm{~cm}^{-1}$ and $1,282 \mathrm{~cm}^{-1}$ suggests azoreductase-mediated cleavage of azo bond (-N=N-) in AB1 dye (Fig. 5B) [1]. The disappearance of sharp intensive bands at $1,331 \mathrm{~cm}^{-1}$ and $642 \mathrm{~cm}^{-1}$ attributing to $\mathrm{S}=\mathrm{O}$ and $\mathrm{C}-\mathrm{S}$ bonds represents the removal of highly polar sulfo ( $\mathrm{R}^{-\mathrm{SO}_{3}}{ }^{-}$) group in $\mathrm{AB} 1$ dye and formation of less polar byproducts. In the FTIR spectra of degradation products, the appearance of new vibrational bands at 1,652 and 1416 $\mathrm{cm}^{-1}$ (aromatic $\left.\mathrm{C}=\mathrm{C}\right), 1,589 \mathrm{~cm}^{-1}\left(-\mathrm{NH}_{2}\right), 3,452 \mathrm{~cm}^{-1}(-\mathrm{OH})$, and $1,579 \mathrm{~cm}^{-1}\left(-\mathrm{NO}_{2}\right)$, signifying the presence of aromatic hydrocarbons with nitro and amine substituted functional groups [1]. After that, the detection of degraded byproducts of AB1 via LC-MS confirms the azoreductasemediated reductive cleavage of the dye (Supplementary Fig. S6 and Fig. S7). 4-Nitroaniline (RT $2.7 \mathrm{~min}, \mathrm{~m} / \mathrm{z}$ 138.06) and naphthalene-1,2,8-triol (RT $2.45 \mathrm{~min}, \mathrm{~m} / \mathrm{z}$ 176.1) are formed due to azoreductase-mediated symmetrical cleavage of the azo bond (Fig. 5C) [1]. Microbes further transformed 4-nitroaniline to 4-nitrophenol (RT $2.36 \mathrm{~min}, \mathrm{~m} / \mathrm{z}$ 139.04), nitrobenzene (RT 2.33 min, m/z 122.04), and 4-aminophenol (RT $1.78 \mathrm{~min}, \mathrm{~m} / \mathrm{z}$ 109.10). Naphthalene-1,2,8-triol was reduced to 1-naphthol (RT $1.7 \mathrm{~min}, \mathrm{~m} / \mathrm{z}$ 144.9). The presence of catechol (RT $2.3 \mathrm{~min}, \mathrm{~m} / \mathrm{z}$ 110.07), a central intermediate of aerobic biodegradation of benzene derivatives, suggests degradation via meta- or ortho-cleavage pathways [69]. 


\section{Plasma membrane-bound ferrireductase enzyme influences algal dye degradation}

We hypothesized that the increase in the rate of azo dye degradation with increased bioavailable iron has an association with higher activity of cellular azoreductase per cell or higher activity of azoreductase due to an increase in cell numbers. Therefore, axenic algal and algal-bacterial consortium were subjected to different Fe concentrations, and their effect on the algal cell growth, enzymatic activities, and iron uptake was assessed. With the increase in iron concentration, algal cell growth showed a considerable increase (Fig. 6A). In axenic cultures, C. sorokiniana growth varied with Fe concentration in the experimental setup, $2 \times 10^{-6} \mathrm{M} \mathrm{Fe}$ : $8 \times 10^{7}$ cells $\mathrm{mL}^{-1}, 1 \times 10^{-6} \mathrm{M}$ Fe: $6 \times 10^{7}$ cells $\mathrm{mL}^{-1}$; and $1 \times 10^{-7} \mathrm{M} \mathrm{Fe}: 1.4 \times 10^{7}$ cells $\mathrm{mL}^{-1}$. At lower Fe concentrations, $R$. pickettii PW2 enhances the growth of $C$. sorokiniana. The effect of the siderophore-producing bacteria in enhancing algal growth at lower Fe concentrations was also significant on growth parameters, such as growth rate (r): $p=0.006$ for $1 \times 10^{-7} \mathrm{M} \mathrm{Fe}$, $p=0.028$ for $1 \times 10^{-6} \mathrm{M} \mathrm{Fe}$; carrying capacity $(\mathrm{k}): p=0.025$ for $1 \times 10^{-7} \mathrm{M} \mathrm{Fe}$; and $p=0.017$ for $1 \times 10^{-6} \mathrm{M} \mathrm{Fe}$, and area under curve (auc): $p=0.003$ for $1 \times 10^{-7} \mathrm{M} \mathrm{Fe}$; and $p=0.001$ for $1 \times 10^{-6} \mathrm{M}$ Fe (Supplementary Fig. S8, Table S8, and Table S9). However, at $2 \times 10^{-6} \mathrm{M} \mathrm{Fe,} \mathrm{microalgae,}$ grown axenically and in the consortium, lack a significant difference in their growth parameters ( $p=0.157$ for $\mathrm{r}, p=0.551$ for $\mathrm{k}$, and $p=0.444$ for auc). Also, $\mathrm{NO}_{3}-\mathrm{N}$ concentration in axenic algal and algal-bacterial setups differ insignificantly even after 14 days, suggesting the cells are not nitrogen depleted.

Though algal cell density increases at high Fe concentration, the dye degradation rate significantly decreases (Figs. 4b, 7a). In C. sorokiniana, membrane-bound ferrireductase activity reduces with increasing iron concentration (Fig. 6B) [70]. Also, siderophore-producer R. pickettii PW2 significantly increased ferrireductase activity in microalgae at lower $\mathrm{Fe}$ concentrations $\left(1 \times 10^{-7} \mathrm{M} \mathrm{Fe}: p=0.001\right.$; and $\left.1 \times 10^{-6} \mathrm{MFe}: p=0.003\right)$ (Supplementary Table S10). Ferrireductases reduce $\mathrm{Fe}^{3+}$-siderophore complexes to release bioavailable $\mathrm{Fe}^{2+}$, which can be directly engulfed via an endocytosis-mediated non-reductive pathway [19, 71]. In contrast, despite a considerable increase in microalgal growth in the consortium at a high $\mathrm{Fe}$ concentration, the ferrireductase activity lacked any significant increase (Fig. 6B), which could be a potential shift in an iron-uptake mechanism. At higher Fe concentrations, bacteria use ferric iron via direct diffusion across the cell membrane than via high-affinity iron uptake by 
producing siderophore and chelating iron [33, 39]. Similar to bacteria, at high iron availability, microalgae follow a non-reductive direct iron-uptake pathway triggered by the difference in intracellular and extracellular iron concentration (Supplementary Fig. S9) [72, 73].

Our results demonstrate an association between siderophore-mediated bioavailable iron and algal ferrireductase activity. In contrast with axenic culture, microalgal cell surface EPS accumulates iron significantly more when co-cultured with bacteria $(t$-test; $p<0.05)$ (Fig. 6C) but only at low Fe concentrations: $1 \times 10^{-7} \mathrm{M}$ and $1 \times 10^{-6} \mathrm{M}$, indicating iron accumulation is a stress response (Supplementary Fig. S9) [72]. Algae do not produce siderophores; however, they increase iron in the phycosphere by biosorption and chelation onto extracellular polymeric substances, including mono- and polysaccharides [20]. Iron accumulation at the surface acts as a signal for ferric-assimilating proteins (FEA1 and FEA2) to assimilate the chelated iron for intracellular uptake via ferrireductase-dependent reductive pathway (Supplementary Fig. S9), which has also been shown in marine microalga Chromera velia [74], and in Chlorella sorokiniana UTEX 1602 (Supplementary Table S13 and Table S14).

Iron serves as an essential micronutrient in microbes; however, the association between bioavailable iron and microbial efficacy to degrade azo dye has not been explored previously. To examine the effect of ferrireductase, microalgal cells were pretreated with 50 $\mu \mathrm{M}$ Diphenyleneiodonium (DPI), a known inhibitor. DPI prevents the transfer of an electron from ferrireductase (flavohemoproteins; Fre1) to the Fe-chelate, thereby inhibiting $\mathrm{Fe}^{3+}$ to $\mathrm{Fe}^{2+}$ reduction, thus, inhibiting ferrireductase activity $(p=0.00)$ (Fig. 6D and Supplementary Table S11) $[49,50,73]$. DPI $(50 \mu \mathrm{M})$ significantly inhibited microalgal azoreductase both in the presence $(\mathrm{Fe}+\mathrm{DPI}+)(p=0.008)$ and absence (Fe-DPI-) $(p=0.035)$ of iron (Supplementary Table S12). However, C. sorokiniana, if not pretreated with DPI (Fe-DPI-), retained significant azoreductase activity, which was further increased after iron supplementation (Fe+DPI-) $(p=0.012)$ (Fig. 6D). We report NAD(P)H-dependent azoreductase in $C$. sorokiniana lacking sensitivity to oxygen in complete photoautotrophic culture conditions [29], which adds to its benefits for industrial sustainability.

In Saccharomyces cerevisiae, an association between azoreductase and ferrireductase activities has been shown [75]; however, such association has never been explored in microalgae. Azoreductase in S. cerevisiae shows a high dependency on the Fre1p component of metalloregulator ferrireductase (FRE1). Transmembrane ferric-chelate reductases having high 
sequence similarity have also been reported in green microalga $C$. sorokiniana UTEX 1602 and Chlamydomonas reinhardtii (Supplementary Fig. S10, Table S13, and Table S14). Taken together, we propose that the ferrireductase-mediated reductive pathway is vital for azoreductase in $C$. sorokiniana, though it requires further investigation in understanding the exact role of extracellular iron-concentration in driving the oxidoreductases enzymatic machinery in Chlorella. Typically, textile wastewater bioremediation studies treat systems as black boxes. A poor understanding of the extracellular environment, especially the role of micronutrients, has posed a major limitation in their industrial translation. In this work, extracellular iron concentration not only influences the plasma-membrane bound ferrireductase pathway in Chlorella, which sustains such inter-kingdom mutualism but also azoreductase-mediated dye degradation.

Recent photobioreactor-based comprehensive studies on algal-bacterial respiration, COD removal, and nitrification have further highlighted the potential of such inter-kingdom symbionts in replacing the non-specific bacterial processes in industries [30]. Bacterial azoreductases, which in general are oxygen-sensitive, require a complex two-stage design to integrate into the current industrial infrastructure. In contrast, Chlorella has been reported to modify extracellular oxygen in contrasting dark (oxygen-deprived conditions favoring dye degradation) and light (oxygenated conditions favoring aromatic amines degradation) cycles accelerate dye degradation [12], and provide oxygen for bacterial growth and COD removal in municipal wastewater [30]. In our work, the Chlorella-Ralstonia consortium showed a higher algal growth rate ( $\sim 2$ times) and dye degradation rate ( $\sim 2$ times) compared to monocultured alga. The consortium also overcame iron limitation and carbon availability and performed under varied $\mathrm{pH}$ ( $\mathrm{pH} 6$ to 9) and dye concentrations. Therefore, we propose that such algal-bacterial mutualistic associations could form a stable and robust bioremediation system that overcomes the current limitations of biological designs for textile industry wastewater treatment.

In conclusion, a consortium of Chlorella sorokiniana and Ralstonia pickettii PW2 represents a symbiotic association based on the exchange of specific limiting nutrients (Fig. 7). C. sorokiniana receives iron from $R$. pickettii PW2 in exchange for dissolved organic matter to develop a barter system. Under iron stress, bacterial siderophore ensures iron availability promoting algal growth rate and extracellular dye degradation. Therefore, a bacterial-algal association has the potential for wastewater treatment under iron-limiting conditions compliant with green chemistry principles. We report the transmembrane ferrireductase activity in $C$. 
sorokiniana, which plays a crucial role in a reductive iron-uptake pathway involving azoreductase. Bioavailable iron regulates the co-expression of the two oxidoreductase pathways. Microalgal-bacterial consortium works under photoautotrophic conditions would provide a self-sustainable alternative to current microbial dye remediation processes. Further studies on microalgal-bacterial mutualisms will help develop methods to overcome the limitations of micronutrient availability in industrial bioprocesses and bioremediation.

\section{Materials and Methods}

\section{Culture media preparation, sample collection, and bacterial identification}

The three freshwater algal strains were screened in this study, Chlorella sorokiniana (CCAP 211/8K), Scenedesmus sp., and Oscillatoria animalis (Sciento Ltd), were cultivated in Bold's Basal Medium ( $3 \mathrm{~N}-\mathrm{BBM}+\mathrm{V}$; henceforth referred to as $\mathrm{BBM})$ and maintained with EDTA chelated iron at $28^{\circ} \mathrm{C}$ under continuous white light (Fig. 1B). Two strains of the marine microalga Phaeodactylum tricornutum 1052/6 and 1055/1 were grown on sterile $f / 2$ medium [36]. $\mathrm{FeCl}_{3} \cdot 6 \mathrm{H}_{2} \mathrm{O}$ was used as an iron source; however, 10-folds Na-EDTA was used as a chelating agent only when specified. The iron-abundant BBM is referred to as $\mathrm{BBM}+\mathrm{Fe}$ (EDTA-chelated) and iron-deficient as BBM-Fe (not EDTA-chelated).

Textile wastewater was collected from the industrial area in Panipat, India (29.363121 N, $76.992971 \mathrm{E}$ ). The non-selective $10 \%$ tryptone soya agar (TSA) plates supplemented with 0.014\% triphenyl tetrazolium chloride (TTC) was used to isolate bacteria from textile wastewater [37] (Fig. 1A). The morphologically distinct colonies were purified and identified as Serratia plymuthica PW1, Ralstonia pickettii PW2, Stenotrophomonas rhizophila PW3, S. maltophilia PW5, S. maltophilia PW6, Serratia liquefaciens PW71, and Stenotrophomona rhizophila PW72 using 16S rRNA sequence analyses (Table 1) [38]. Genomic DNA of bacteria was isolated and purified using Wizard Genomic DNA Purification Kit (Promega, USA). 16S rRNA gene was amplified using PCR with universal primers 27F (5'AGAGTTTGATCCTGGCTCAG-3’) and 1492R (5'-TACGGYTACCTTGTTACGACTT-3’) for 30 cycles $\left(94^{\circ} \mathrm{C}\right.$ for $1 \mathrm{~min}, 50^{\circ} \mathrm{C}$ for $1 \mathrm{~min}$, and $72{ }^{\circ} \mathrm{C}$ for $2 \mathrm{~min}$ ). The amplified products were analyzed onto 1\% agarose gel (low EEO) and extracted and purified from the gel using the QIAprep Miniprep Kit (Qiagen, Netherlands). The 16S rRNA sequencing reactions were 
performed using 785F (5'-GGATTAGATACCCTGGTA-3') and 907R (5'CCGTCAATTCCTTTRAGTTT-3'). The homologous sequence was searched in the NCBI GenBank database using BLAST and DNA sequences of identified bacteria were submitted with accession numbers MW857264, MW857265, MW857266, MW857267, MW857268, MW857269, and MW857270. The isolates were revived in 10\% TSB for further experiments (Fig. 1A).

\section{Bacterial siderophore production}

Bacterial siderophore production was estimated using standard Chrome Azurol S (CAS) assays in modified Minimal Medium 9 (MM9) supplemented with casamino acid deferrated with 8hydroxyquinoline, glucose, $\mathrm{MgCl}_{2}$, and $\mathrm{CaCl}_{2}[39,40]$ (Fig. 1C). Siderophore production was ascertained as yellow/orange zone around bacterial colonies on CAS agar plate. Bacterial siderophore was quantified using standard CAS liquid assay using Desferrioxamine mesylate used as standard, and further categorized using Csaky's assay (for hydroxamate type) with Desferrioxamine mesylate and Arnow's assays (for catecholate) with 2’3-Dihydroxybenzoic acid as standards [39].

\section{Algal dye decolorization assessment}

Microalgal potential to degrade Acid Black 1 dye (AB1, Sigma Aldrich; CAS: 1064-48-8) was assessed in their respective growth media (Fig. 1D). Ten-day old algal species cultures were preincubated in EDTA-chelated growth media for $48 \mathrm{~h}$ before adding filter-sterilized $(0.2 \mu) 10$ $\mu \mathrm{M}$ AB1 dye. Microalgal cultures were incubated at $28^{\circ} \mathrm{C}$ under continuous light for $72 \mathrm{~h}$, and cell biomass was removed by centrifuging the culture at $5000 \times g$ for $5 \mathrm{~min}$. The supernatant was used to estimate the dye decolorization by microalgal cultures by calculating the per cent dye removal as follows: [(initial OD $618 \mathrm{~nm}$ - final OD $618 \mathrm{~nm}) /$ initial $\left.\mathrm{OD}_{618 \mathrm{~nm}}\right] \times 100$ [1]. 


\section{Algal-bacterial co-culturability assessment under iron limiting conditions}

To analyze the symbiotic interactions in iron-limiting environment, dye-decolorizer microalgae (Chlorella sorokiniana/Scenedesmus sp.) were co-cultured with siderophore-producing bacteria (Serratia plymuthica PW1/Ralstonia pickettii PW2/Stenotrophomonas maltophilia PW5/S. maltophilia PW6/S. liquefaciens PW71), and their growth characteristics were determined. An overnight bacterial culture raised in 10\% TSB was washed three times with sterile $\mathrm{BBM}-\mathrm{Fe}$. Bacterial suspension in $\mathrm{BBM}-\mathrm{Fe}\left(\mathrm{OD}_{600 \mathrm{~nm}}=0.3\right)$ was inoculated in microalgal exudates obtained by filter sterilization $(0.2 \mu)$ of 7 -day old algal culture raised BBM+Fe. The bacterial growth $\left(\mathrm{OD}_{600 \mathrm{~nm}}\right)$ was taken as a measure of the potential of bacterial isolate to use algal-derived dissolved organic matter (DOM) as a carbon source (Fig. 1E).

Bacterial isolates showing survival and growth in microalgal exudates were selected to ascertain their co-culturability [19] (Fig. 1F). Overnight cultures of bacterial isolates raised in $\mathrm{BBM}+\mathrm{Fe}$ supplemented with $0.1 \%$ glucose were washed with sterile BBM-Fe, and $1 \mathrm{ml}$ of bacterial suspensions $\left(\mathrm{OD}_{600}=0.5\right)$ were inoculated in $20 \mathrm{ml}$ of 1-day old cultures of microalgae raised in iron-deficient $\left(1 \times 10^{-6} \mathrm{M} \mathrm{FeCl}_{3}\right) \mathrm{BBM}-\mathrm{Fe}$ media [33, 41]. Growth and morphological characteristics of both microalgal and bacterial co-inoculants were observed to determine the mutualistic, antagonistic, or neutral interactions. Bacterial and algal cells were determined periodically over 12 days on agar plates (CFUs) and under the microscope using a hemocytometer, respectively [19]. The algal growth curve was fitted in the logistic equation to determine the growth characteristics (growth rate ' $r$ ', carrying capacity ' $\mathrm{k}$ ', doubling time 'Dt', and area under curve 'auc') using the growth prediction modeling package 'growthcurver' in $\mathrm{R}[42]$.

The significance of co-inoculation of siderophore producer bacteria on microalgal growth was statistically analyzed using One-Way ANOVA, Tukey's post-hoc test, and Principal Component Analysis (PCA). Bacterial and microalgal isolates showing mutualistic associations were designated as a 'consortium' for further experiments on azo dye degradation (Fig. 1G).

\section{Characterization of carbohydrates in algal exopolysaccharides (EPS)}


The exopolysaccharides (EPS) from C. sorokiniana and Scenedesmus sp. were fractionated using Dowex Marathon C cation exchange resin (Sigma Aldrich, USA) [43]. The algal cells from a 7-day old culture in BBM-Fe were washed and centrifuged at $2000 \times g$ for $3 \mathrm{~min}$ at RT. The cell pellets were resuspended in PBS buffer containing Dowex Marathon C $\left(25 \mathrm{~g} \mathrm{~g}^{-1}\right)$ and gently mixed in a rotatory mixer $(50 \mathrm{RPM})$ at $4^{\circ} \mathrm{C}$ for $1 \mathrm{~h}$. Subsequently, the algal cells were centrifuged at $4000 \times \mathrm{g}$ for $4 \mathrm{~min}$, and the supernatant was subjected to overnight precipitation of exopolysaccharides in $70 \%$ ethanol $\left(3: 1\right.$ to supernatant) at $4^{\circ} \mathrm{C}$ [44]. Thereafter, the supernatant was centrifuged at $10,000 \times \mathrm{g}$ for $10 \mathrm{~min}$, and the pellet was collected for analyses by high-performance anion-exchange chromatography (HPAEC). The pellets were acid hydrolyzed with $72 \% \mathrm{H}_{2} \mathrm{SO}_{4}$ at $121^{\circ} \mathrm{C}$ for $30 \mathrm{~min}$ in an autoclave. Monosaccharides present in hydrolyzed EPS were identified using Ion Chromatography System (Thermo Scientific Dionex ICS 5000+, UK) with AminoPac PA10 column $(250 \mathrm{~mm} \times 4 \mathrm{~mm})$ and a pulsed amperometric detector. $\mathrm{KOH}(1 \mathrm{mM})$ was used for isocratic elution and separation at $0.25 \mathrm{~mL} \mathrm{~min}{ }^{-1}$ for 25 min. Arabinose, fructose, galactose, glucose, mannose, and rhamnose were used as standards.

\section{Challenging algal-bacterial consortium under varying environmental conditions}

To evaluate the performance of the microalgal-bacterial consortium in degrading dye, three experimental setups in $\mathrm{BBM}+\mathrm{Fe}$ and $\mathrm{BBM}-\mathrm{Fe}$ were conducted: (i) setup 1: axenic microalgal, (ii) setup 2: microalgal-bacterial consortium, and (iii) setup 3: axenic bacterial (supplemented with $0.01 \%$ glucose) (Supplementary Table S3). The microalgal cells, previously grown in $\mathrm{BBM}+\mathrm{Fe}$ under static conditions at $28^{\circ} \mathrm{C}$ in continuous light, were washed and used in all the experiments. $\mathrm{FeCl}_{3}\left(1 \times 10^{-6} \mathrm{M}\right)$ was supplied to maintain the iron-deficient environment, whereas AB1 dye $(20 \mu \mathrm{M})$ was filter-sterilized $(0.2 \mu)$ in the experimental setups. The dye decolorization in different experimental setups was assessed for $144 \mathrm{~h}$ by using the linear regression equation obtained from the standard curve of $\mathrm{AB} 1$ dye [1]. The rate of $\mathrm{AB} 1$ degradation was calculated by fitting the concentration data in kinetic models using 'mkin' package in R [45].

To identify the factors governing the rate of dye degradation, a multi-factor study using Taguchi's $\mathrm{L}_{16}\left(4^{3}\right)$ orthogonal array design was developed. Thirty-two experiments were conducted in setups 1 (axenic algal) and setup 2 (algal-bacterial consortium) with varying concentrations of $\mathrm{Fe}, \mathrm{AB} 1$ dye, and $\mathrm{pH}$ computed using Minitab ver. 19, as outlined elsewhere 
[46]. Details of variables/levels were as follows: Fe: $1 \times 10^{-7}, 1 \times 10^{-6}, 2 \times 10^{-6}$, and $5 \times 10^{-6} \mathrm{M}$; $\mathrm{pH}$ : 6.0, 7.0, 8.0, and 9.0, and (iii) dye: $4 \mu \mathrm{M}, 8 \mu \mathrm{M}, 12 \mu \mathrm{M}$, and $16 \mu \mathrm{M}$ (Supplementary Table S5).

Microalgal cells were previously starved for iron in BBM-Fe media for $24 \mathrm{~h}$ at various $\mathrm{pH}$ levels as per the $\mathrm{L}_{16}$ design (Supplementary Table S5). For experiments in setup 2, a microbial consortium was developed by mixing an overnight culture of siderophore-producer bacterial isolate $(\mathrm{OD}=0.3)$ with microalgal cells $(1 \% \mathrm{v} / \mathrm{v})$. The culture was spiked with different concentrations of iron $\left(\mathrm{FeCl}_{3} \cdot 6 \mathrm{H}_{2} \mathrm{O}\right)$ and $\mathrm{AB} 1$ dye as per orthogonal array design and maintained under static conditions at $28^{\circ} \mathrm{C}$ with continuous light (Supplementary Table S5). Uninoculated BBM-Fe was kept as controls. Microbial cells were carefully separated, and culture media was sampled periodically over $48 \mathrm{~h}$; dye concentration was determined in different experimental setups [1]. Also, the rate of $\mathrm{AB} 1$ degradation was calculated by fitting the concentration data in the first-order kinetic model using ' $m$ kin' package [45, 47]. Variations in dye degradation in different setups were analyzed by multiple linear regression model using Minitab ver. 19, and the effect of varying levels of different factors on the rate of $\mathrm{AB} 1$ degradation was determined. The half-life of AB1 dye, the time at which $50 \%$ of dye gets degraded, and the chi-square $\left(\chi^{2}\right)$ error level representing the goodness-of-fit of the kinetic model was also determined. A $\chi^{2}$ of $<15$ is considered as an acceptable fit [45].

\section{Assessment of algal ferrireductase, azoreductase activity, and iron concentration}

Ferrireductase activity was determined in microalgae raised axenically and in consortium with siderophore-producer bacteria under different iron concentrations $\left(\mathrm{FeCl}_{3} \cdot 6 \mathrm{H}_{2} \mathrm{O}: 1 \times 10^{-7} \mathrm{M}\right.$, $1 \times 10^{-6} \mathrm{M}$, and $2 \times 10^{-6} \mathrm{M}$ ). The growth characteristics (carrying capacity, growth rate, doubling time, and area under curve) of microalgal cells were observed using the 'growthcurver' package as described in section 2.4. After ten days of incubation, the microalgal cells were harvested, washed, and resuspended in PBS. An equal number of microalgal cells were maintained in all

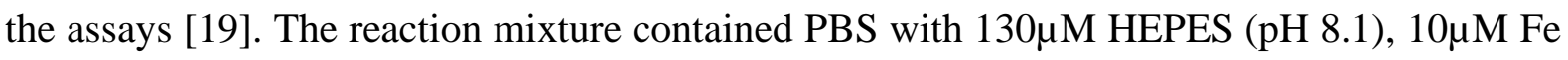
(with 10-folds EDTA), and $100 \mu \mathrm{M}$ bathophenanthrolinedisulfonic acid or BPDS, i.e., $\mathrm{Fe}^{2+}$ chelator. The ferrireductase activity was estimated as the formation of the $\mathrm{Fe}^{2+}$-BPDS complex at $\mathrm{OD}_{535 \mathrm{~nm}}$ using the extinction coefficient $22140 \mathrm{M}^{-1} \mathrm{~cm}^{-1}$. 
Simultaneously, the cellular concentration of iron in microalgae was estimated using ICP-MS. The culture was centrifuged at $4000 \times \mathrm{g}$ for $4 \mathrm{~min}$, and the cells were removed, washed, and resuspended in sterile deferrated BBM. Microalgal cells were acid digested in $70 \% \mathrm{HNO}_{3}$ and appropriately diluted for estimating iron content by ICP-MS (Bruker M90 ICP-MS). To estimate iron on the cell surface, microalgal EPS was extracted as described in section 2.5. The EPS was also digested in $70 \% \mathrm{HNO}_{3}$ and diluted for estimating the $\mathrm{Fe}$ by ICP-MS. $\mathrm{FeCl}_{3}$ was used as a standard.

The azoreductase activity of microalgal cells was determined after 10 days of incubation, as described previously [48]. To confirm the expression of azoreductase in the microalgae during dye degradation, the microalgal cells from different setups were pretreated with ferrireductase inhibitor, i.e., Diphenyleiodonium (DPI) [49, 50]. The optimum concentration of DPI was determined by ferrireductase assay using microalgal cells pretreated with different concentrations of DPI $(50,100$, and $150 \mu \mathrm{M})$ for $1 \mathrm{~h}$. Excessive DPI was removed by a thorough washing of the cells, and azoreductase assay was carried out in a reaction buffer containing $50 \mathrm{mM}$ phosphate buffer ( $\mathrm{pH}$ 7.2) and $10 \mu \mathrm{M}$ AB1 dye. The reaction was initiated by adding $0.5 \mathrm{mM} \mathrm{NAD}(\mathrm{P}) \mathrm{H}$. The enzyme activity was determined by a decrease in $\mathrm{OD}_{618 \mathrm{~nm}}$ over $240 \mathrm{~min}$. Azoreductase activity was monitored at varying conditions of $\mathrm{Fe}$ (EDTA-chelated) and DPI concentration, i.e., Fe-DPI-, Fe+DPI-, Fe-DPI+, and Fe+DPI+. Linear regression model and One-Way ANOVA were used to analyze variations in the enzyme activities in different experimental setups.

\section{Assessment of microbe-mediated AB1 degradation pathway}

The AB1 degradation pathway in an experimental setup with the microalgal-bacterial consortium was analyzed using analytical techniques. Microbial consortia cultivated in BBMFe were challenged with $\mathrm{AB} 1$ dye in the presence of $1 \times 10^{-6} \mathrm{M} \mathrm{FeCl}_{3}$. Aliquots of culture were sampled aseptically at a regular time interval of the treatment by removing the microbial cells by centrifuging the culture at $10000 \times g$ for $15 \mathrm{~min}$. The supernatant was filtered through a 0.2 $\mu \mathrm{m}$ filter, and the filtrate was analyzed by UPLC (Waters Acquity UPLC system, United States) using BEH C18 100mm $\times 2.1 \mathrm{~mm}$ column fitted with a photodiode array detector. Acetonitrile with $0.2 \%$ formic acid in water $(85: 15 \mathrm{v} / \mathrm{v})$ was used as a mobile phase, and the peaks were recorded at $\mathrm{OD}_{595 \mathrm{~nm}}$. $\mathrm{AB} 1$ dye was used as a standard. 
To decipher the possible dye-degradation pathway, AB1 degradation products in the different experimental setups were extracted using sequential solvent extraction and characterized and identified using different analytical techniques [1]. After dye decolorization, the microbial cells were pelleted $(10,000 \times g$ for $15 \mathrm{~min}$ at RT), and the supernatant was filtered through a $0.2 \mu$ filter. The degraded products of the dye in the filtrate were extracted with an equal volume of ethyl acetate (Sigma Aldrich; HPLC grade) and dried over sodium sulphate $\left(\mathrm{Na}_{2} \mathrm{SO}_{4}\right)$. Ethyl acetate was then evaporated using a rotary evaporator (Heidolph Laborota 4000, Germany) at $47^{\circ} \mathrm{C}$ under reduced pressure [1]. The dried metabolites were solubilized in a minimum volume of acetone subjected to FTIR analysis. Spectroscopically pure $\mathrm{KBr}$ was mixed with the samples (dissolved in HPLC grade acetone) in a ratio of 5:95 and analyzed at the mid-IR region (400$4,000 \mathrm{~cm}^{-1}$ ) of the spectrometer (Perkin Elmer Spectrum 100, United States). The biodegraded products of $\mathrm{AB} 1$ were identified using LC-MS analyses (Dionex Ultimate 3000) with acetonitrile: water (70:30) as a solvent system. The sample dissolved in HPLC grade methanol was injected in UHPLC (Hypersil Gold) using $5 \mu \mathrm{m}, 100 \mathrm{~cm} \times 2.1 \mu \mathrm{m}$ column for a run time of 0 to $20 \mathrm{~min}$ at a positive polarity $(+1)$ mode. The mass spectra were recorded within a range of $100-1200 \mathrm{~m} / \mathrm{z}$ with a maximum ion transfer time of $100 \mathrm{~ms}$. Degraded products of AB1 dye were identified by analyzing mass fragment peaks and referring to NIST (National Institute of Standards and Technology), ChemSpider, and $\mathrm{m} / \mathrm{z}$ cloud libraries and the existing literature. 


\section{Acknowledgements}

V.M. express gratitude towards the Department of Science and Technology, Technology Mission Division (Energy, Water \& Others), India, for the financial support "Development of a novel single-stage . . . . environmental safety' under Optimal Water Use in Industrial Sector. V.M. and R.S.S also thank the Institute of Eminence for Faculty Research Project Grant. B.P. acknowledges support from the Winston Churchill Memorial Trust and the EPSRC Global Challenges Research Fund. D.R. thanks University Grant Commission, Government of India for providing Junior Research Fellowship, British Council, India, Newton Fund, UK, and Department of Biotechnology, Government of India, for Newton-Bhabha PhD placement award 2017-18. U.S. and P.P acknowledge the University Grant Commission for Junior Research Fellowship.

\section{Conflict of interest}

All the authors unanimously declare lack of any competing financial and/or non-financial interests in relation to the work described in the MS.

\section{Author contributions}

D.R., V.M., B.P. and R.S.S conceived the experiments; D.R. performed the experiments; U.S., P.P., and A.F. contributed in siderophore method, multi-factor study, and ICP-MS study respectively; D.R. undertook data analysis; D.R., V.M., R.S.S. and B.P. wrote the manuscript.

\section{Data availability}

The bacterial 16S rRNA sequencing data is available at the National Center for Biotechnology Information (NCBI) under submission accession number SUB9427182. 


\section{References}

1. Rawat D, Sharma RS, Karmakar S, Arora LS, Mishra V. Ecotoxic potential of a presumably non-toxic azo dye. Ecotoxicol Environ Saf 2018; 148: 528-537.

2. Landrigan PJ, Fuller R, Acosta NJR, Adeyi O, Arnold R, Basu N (Nil), et al. The Lancet Commission on pollution and health. Lancet 2018; 391: 462-512.

3. Mishra V, Sharma U, Rawat D, Benson D, Singh M, Sharma RS. Fast-changing lifestyles and ecotoxicity of hair dyes drive the emergence of hidden toxicants threatening environmental sustainability in Asia. Environ Res 2020; 184: 109253.

4. Rawat D, Mishra V, Sharma RS. Detoxification of azo dyes in the context of environmental processes. Chemosphere 2016; 155: 591-605.

5. Solís M, Solís A, Pérez HI, Manjarrez N, Flores M. Microbial decolouration of azo dyes: A review. Process Biochem 2012; 47: 1723-1748.

6. Baglieri A, Sidella S, Barone V, Fragalà F, Silkina A, Nègre M, et al. Cultivating Chlorella vulgaris and Scenedesmus quadricauda microalgae to degrade inorganic compounds and pesticides in water. Environ Sci Pollut Res 2016; 23: 18165-18174.

7. Li K, Liu Q, Fang F, Luo R, Lu Q, Zhou W, et al. Microalgae-based wastewater treatment for nutrients recovery: A review. Bioresour Technol 2019; 291: 121934.

8. Ridley CJA, Parker BM, Norman L, Schlarb-Ridley B, Dennis R, Jamieson AE, et al. Growth of microalgae using nitrate-rich brine wash from the water industry. Algal Res 2018; 33: 91-98.

9. Stoffels L, Finlan A, Mannall G, Purton S, Parker B. Downstream Processing of Chlamydomonas reinhardtii TN72 for Recombinant Protein Recovery. Front Bioeng Biotechnol 2019; 7.

10. Malik S, Hagopian J, Mohite S, Lintong C, Stoffels L, Giannakopoulos S, et al. Robotic Extrusion of Algae-Laden Hydrogels for Large-Scale Applications. Glob Challenges 2019; 1900064.

11. Fuldauer LI, Parker BM, Yaman R, Borrion A. Managing anaerobic digestate from 
food waste in the urban environment: Evaluating the feasibility from an interdisciplinary perspective. J Clean Prod 2018; 185: 929-940.

12. Sun J, Hu Y, Li W, Zhang Y, Chen J, Deng F. Sequential decolorization of azo dye and mineralization of decolorization liquid coupled with bioelectricity generation using a pH self-neutralized photobioelectrochemical system operated with polarity reversion. J Hazard Mater 2015; 289: 108-117.

13. Wang Y, Ho SH, Cheng CL, Guo WQ, Nagarajan D, Ren NQ, et al. Perspectives on the feasibility of using microalgae for industrial wastewater treatment. Bioresour Technol 2016; 222: 485-497.

14. Qiu Y, Wang Z, Liu F, Wu Z, Chen H, Tang D, et al. Effect of complex iron on the phosphorus absorption by two freshwater algae. Environ Technol 2020; Mar: 1-9.

15. Yaseen DA, Scholz M. Textile dye wastewater characteristics and constituents of synthetic effluents: A critical review. Int J Environ Sci Technol 2019; 16: 1193-1226.

16. Kraemer SM. Iron oxide dissolution and solubility in the presence of siderophores. Aquat Sci 2004; 66: 3-18.

17. Morrissey J, Bowler C. Iron utilization in marine cyanobacteria and eukaryotic algae. Front Microbiol 2012; 3: 43.

18. Shaked Y, Lis H. Disassembling iron availability to phytoplankton. Front Microbiol 2012; 3: 123.

19. Amin SA, Green DH, Hart MC, Kupper FC, Sunda WG, Carrano CJ. Photolysis of iron-siderophore chelates promotes bacterial-algal mutualism. Proc Natl Acad Sci 2009; 106: 17071-17076.

20. Amin SA, Hmelo LR, Van Tol HM, Durham BP, Carlson LT, Heal KR, et al. Interaction and signalling between a cosmopolitan phytoplankton and associated bacteria. Nature 2015; 522: 98-101.

21. Ramanan R, Kim BH, Cho DH, Oh HM, Kim HS. Algae-bacteria interactions: Evolution, ecology and emerging applications. Biotechnol Adv 2016; 34: 14-29. 
22. Malhotra S, Mishra R, Karmakar S, Rawat D, Sharma S, Singh S, et al. Environmental factors shaping plant-microbe associations: Their significance to improve plant health and vegetation restoration in degraded lands. In: Ansari MW, Kumar S, Kaula BC, Wattal RK (eds). Introduction to challenges and strategies to improve crop productivity in changing environment, 1st ed. 2018. Enriched Publications Pvt. Ltd., New Delhi.

23. Zuñiga C, Li T, Guarnieri MT, Jenkins JP, Li CT, Bingol K, et al. Synthetic microbial communities of heterotrophs and phototrophs facilitate sustainable growth. Nat Commun 2020; 11: 1-13.

24. Grant MA, Kazamia E, Cicuta P, Smith AG. Direct exchange of vitamin B 12 is demonstrated by modelling the growth dynamics of algal-bacterial cocultures. ISME $J$ 2014; 8: 1418-1427.

25. Kazamia E, Helliwell KE, Purton S, Smith AG. How mutualisms arise in phytoplankton communities: building eco-evolutionary principles for aquatic microbes. Ecol Lett 2016; 19: 810-822.

26. Borchert E, Hammerschmidt K, Hentschel U, Deines P. Enhancing Microbial Pollutant Degradation by Integrating Eco-Evolutionary Principles with Environmental Biotechnology. Trends Microbiol 2021; 0.

27. Shahab RL, Brethauer S, Davey MP, Smith AG, Vignolini S, Luterbacher JS, et al. A heterogeneous microbial consortium producing short-chain fatty acids from lignocellulose. Science (80- ) 2020; 369: eabb1214.

28. Liu J, Tan K, He L, Qiu Y, Tan W, Guo Y, et al. Effect of limitation of iron and manganese on microalgae growth in fresh water. Microbiology 2018; 164: 1514-1521.

29. Misal SA, Gawai KR. Azoreductase: a key player of xenobiotic metabolism. Bioresour Bioprocess 2018; 5.

30. Petrini S, Foladori P, Donati L, Andreottola G. Comprehensive respirometric approach to assess photosynthetic, heterotrophic and nitrifying activity in microalgal-bacterial consortia treating real municipal wastewater. Biochem Eng J 2020; 161: 107697. 
31. West SA, Cooper GA. Division of labour in microorganisms: An evolutionary perspective. Nat Rev Microbiol 2016; 14: 716-723.

32. Yarimizu K, Cruz-López R, Carrano CJ. Iron and harmful algae blooms: Potential algal-bacterial mutualism between Lingulodinium polyedrum and Marinobacter algicola. Front Mar Sci 2018; 5: 180.

33. Miethke M, Marahiel MA. Siderophore-based iron acquisition and pathogen control. Microbiol Mol Biol Rev 2007; 71: 413-451.

34. Chomicki G, Kiers ET, Renner SS. The Evolution of Mutualistic Dependence. Annu Rev Ecol Evol Syst 2020; 51: 409-432.

35. Sharma RS, Karmakar S, Kumar P, Mishra V. Application of filamentous phages in environment: A tectonic shift in the science and practice of ecorestoration. Ecol Evol 2019; 9: 2263-2304.

36. CCAP. List of media used to maintain strains at CCAP. Culture Collection of Algae and Protozoa. https://www.ccap.ac.uk/index.php/media-recipes/. Accessed 15 Mar 2021.

37. Kurm V, Van Der Putten WH, Hol WHG. Cultivation-success of rare soil bacteria is not influenced by incubation time and growth medium. PLoS One 2019; 14.

38. Sharma M, Mishra V, Rau N, Sharma RS. Functionally diverse rhizobacteria of Saccharum munja (a native wild grass) colonizing abandoned morrum mine in Aravalli hills (Delhi). Plant Soil 2011; 341: 447-459.

39. Payne SM. Detection, isolation, and characterization of siderophores. Methods Enzymol 1994; 235: 329-344.

40. Schwyn B, Neilands JB. Universal chemical assay for the detection and determination of siderophores. Anal Biochem 1987; 160: 47-56.

41. Keshtacher-Liebson E, Hadar Y, Chen Y. Oligotrophic bacteria enhance algal growth under iron-deficient conditions. Appl Environ Microbiol 1995; 61: 2439-2441.

42. Sprouffske K, Wagner A. Growthcurver: An R package for obtaining interpretable 
metrics from microbial growth curves. BMC Bioinformatics 2016; 17: 172.

43. Loustau E, Rols JL, Leflaive J, Marcato-Romain CE, Girbal-Neuhauser E. Comparison of extraction methods for the characterization of extracellular polymeric substances from aggregates of three biofilm-forming phototrophic microorganisms. Can J Microbiol 2018; 64: 887-899.

44. Song Z, Lye GJ, Parker BM. Morphological and biochemical changes in Phaeodactylum tricornutum triggered by culture media: Implications for industrial exploitation. Algal Res 2020; 47: 101822.

45. Ranke J, Wöltjen J, Meinecke S. Comparison of software tools for kinetic evaluation of chemical degradation data. Environ Sci Eur 2018; 30: 17.

46. Rao RS, Kumar CG, Prakasham RS, Hobbs PJ. The taguchi methodology as a statistical tool for biotechnological applications: A critical appraisal. Biotechnol J 2008; 3: 510-523.

47. FOCUS. Guidance document on estimating persistence and degradation kinetics from environmental fate studies on pesticides in EU registration. Report of the FOCUS Work Group on Degradation Kinetics, EC Document Reference. Sanco/10058/2005 version 2.0 .2006$.

48. Zahran SA, Ali-Tammam M, Hashem AM, Aziz RK, Ali AE. Azoreductase activity of dye-decolorizing bacteria isolated from the human gut microbiota. Sci Rep 2019; 9.

49. Riganti C, Gazzano E, Polimeni M, Costamagna C, Bosia A, Ghigo D.

Diphenyleneiodonium inhibits the cell redox metabolism and induces oxidative stress. J Biol Chem 2004; 279: 47726-47731.

50. Lesuisse E, Casteras-Simon M, Labbe P. Evidence for the Saccharomyces cerevisiae ferrireductase system being a multicomponent electron transport chain. J Biol Chem 1996; 271: 13578-13583.

51. Khilyas I V., Shirshikova T V., Matrosova LE, Sorokina A V., Sharipova MR, Bogomolnaya LM. Production of siderophores by Serratia marcescens and the role of MacAB efflux pump in siderophores secretion. Bionanoscience 2016; 6: 480-482. 
52. Wongsa P, Tanaka M, Ueno A, Hasanuzzaman M, Yumoto I, Okuyama H. Isolation and characterization of novel strains of Pseudomonas aeruginosa and Serratia marcescens possessing high efficiency to degrade gasoline, kerosene, diesel oil, and lubricating oil. Curr Microbiol 2004; 49: 415-422.

53. Bhatt G, Denny TP. Ralstonia solanacearum iron scavenging by the siderophore staphyloferrin B is controlled by $\mathrm{PhcA}$, the global virulence regulator. J Bacteriol 2004; 186: 7896-7904.

54. Tang X, He LY, Tao XQ, Dang Z, Guo CL, Lu GN, et al. Construction of an artificial microalgal-bacterial consortium that efficiently degrades crude oil. J Hazard Mater 2010; 181: 1158-1162.

55. Wan M, Jin X, Xia J, Rosenberg JN, Yu G, Nie Z, et al. The effect of iron on growth, lipid accumulation, and gene expression profile of the freshwater microalga Chlorella sorokiniana. Appl Microbiol Biotechnol 2014; 98: 9473-9481.

56. Rajapitamahuni S, Bachani P, Sardar RK, Mishra S. Co-cultivation of siderophoreproducing bacteria Idiomarina loihiensis RS14 with Chlorella variabilis ATCC 12198, evaluation of micro-algal growth, lipid, and protein content under iron starvation. $J$ Appl Phycol 2019; 31: 29-39.

57. Mühlenbruch M, Grossart HP, Eigemann F, Voss M. Mini-review: Phytoplanktonderived polysaccharides in the marine environment and their interactions with heterotrophic bacteria. Environ Microbiol 2018; 20: 2671-2685.

58. Tanoi T, Kawachi M, Watanabe MM. Effects of carbon source on growth and morphology of Botryococcus braunii. J Appl Phycol 2011; 23: 25-33.

59. Seymour JR, Amin SA, Raina JB, Stocker R. Zooming in on the phycosphere: The ecological interface for phytoplankton-bacteria relationships. Nat Microbiol 2017; 2: 17065.

60. Watanabe K, Takihana N, Aoyagi H, Hanada S, Watanabe Y, Ohmura N, et al. Symbiotic association in Chlorella culture. FEMS Microbiol Ecol 2005; 51: 187-196.

61. Zhou J, Lyu Y, Richlen ML, Anderson DM, Cai Z. Quorum sensing is a language of 
chemical signals and plays an ecological role in algal-bacterial interactions. CRC Crit Rev Plant Sci 2016; 35: 81-105.

62. Sambles C, Moore K, Lux TM, Jones K, Littlejohn GR, Gouveia JD, et al. Metagenomic analysis of the complex microbial consortium associated with cultures of the oil-rich alga Botryococcus braunii. Microbiologyopen 2017; 6: e00482.

63. Ohnishi Y, Horinouchi S. Extracellular production of a Serratia marcescens serine protease in Escherichia coli. Biosci Biotechnol Biochem 1996; 60: 1551-1558.

64. Yang HY, He CS, Li L, Zhang J, Shen JY, Mu Y, et al. Process and kinetics of azo dye decolourization in bioelectrochemical systems: Effect of several key factors. Sci Rep 2016; 6: 27243.

65. Kramer J, Özkaya Ö, Kümmerli R. Bacterial siderophores in community and host interactions. Nat Rev Microbiol . 2020. Nature Research., 18: 152-163

66. Neilands JB. Siderophores: Structure and function of microbial iron transport compounds. J Biol Chem 1995; 270: 26723-26726.

67. Lohan MC, Aguilar-Islas AM, Franks RP, Bruland KW. Determination of iron and copper in seawater at $\mathrm{pH} 1.7$ with a new commercially available chelating resin, NTA Superflow. Anal Chim Acta 2005; 530: 121-129.

68. Keck A, Klein J, Kudlich M, Stolz A, Knackmuss HJ, Mattes R. Reduction of azo dyes by redox mediators originating in the naphthalenesulfonic acid degradation pathway of Sphingomonas sp. strain BN6. Appl Environ Microbiol 1997; 63: 3684-3690.

69. Fuchs G, Boll M, Heider J. Microbial degradation of aromatic compounds- From one strategy to four. Nat Rev Microbiol 2011; 9: 803-816.

70. Yamaguchi-Iwai Y, Ueta R, Fukunaka A, Sasaki R. Subcellular localization of Aft1 transcription factor responds to iron status in Saccharomyces cerevisiae. J Biol Chem 2002; 277: 18914-18918.

71. Kazamia E, Sutak R, Paz-Yepes J, Dorrell RG, Vieira FRJ, Mach J, et al. Endocytosismediated siderophore uptake as a strategy for Fe acquisition in diatoms. Sci Adv 2018; 4: eaar4536. 
72. Blaby-Haas CE, Merchant SS. The ins and outs of algal metal transport. Biochim Biophys Acta - Mol Cell Res 2012; 1823: 1531-1552.

73. Sutak R, Botebol H, Blaiseau P-L, Léger T, Bouget F-Y, Camadro J-M, et al. A comparative study of iron uptake mechanisms in marine microalgae: Iron binding at the cell surface is a critical step. Plant Physiol 2012; 160: 2271-2284.

74. Sutak R, Šlapeta J, Roman MS, Camadro JM, Lesuisse E. Nonreductive iron uptake mechanism in the marine alveolate Chromera velia. Plant Physiol 2010; 154: 9911000.

75. Ramalho PA, Paiva S, Cavaco-Paulo A, Casal M, Cardoso MH, Ramalho MT. Azo reductase activity of intact Saccharomyces cerevisiae cells is dependent on the Fre1p component of plasma membrane ferric reductase. Appl Environ Microbiol 2005; 71: 3882-8. 
bioRxiv preprint doi: https://doi.org/10.1101/2021.06.15.446916; this version posted June 15, 2021. The copyright holder for this preprint (which was not certified by peer review) is the author/funder. All rights reserved. No reuse allowed without permission.

\section{Figures and Tables}

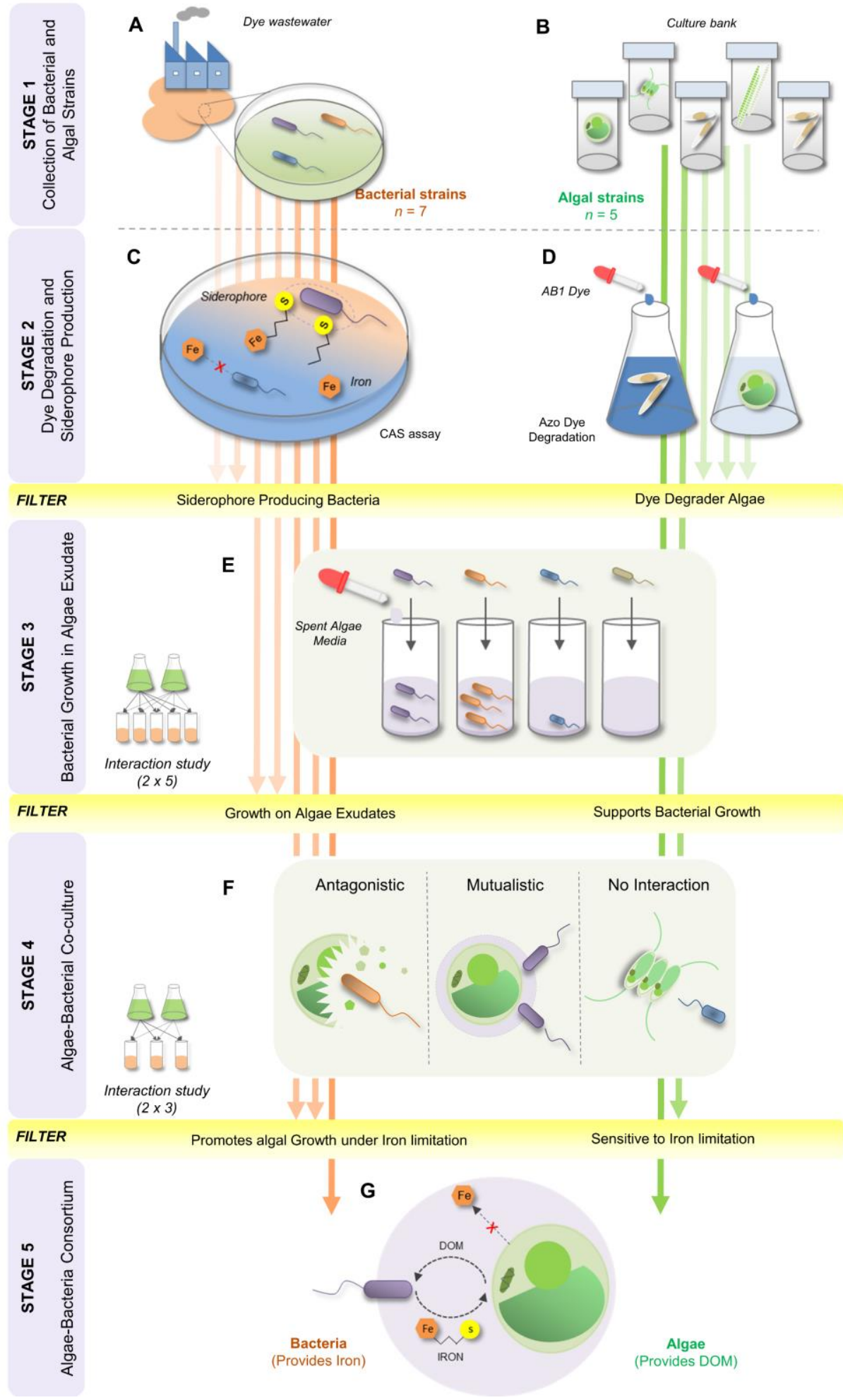


Fig. 1 The study design explaining different stages of experiments to identify a consortium of previously non-associated algae and bacteria. The stages include $\mathbf{A}$ isolation of bacterial strains from textile wastewater collected from Panipat Industrial area, Haryana (India); B cultivation of freshwater and marine algal strains; $\mathbf{C}$ assessment of siderophore production in bacterial strains using Schwyn and Neilands's universal Chrome Azurol S (CAS) assay; D assessment of dye degradation potential of algae strains using Acid Black 1 (AB1) dye; $\mathbf{E}$ interaction study between siderophore producing bacteria and dye degrader microalgae to identify bacterial strains that could sustain on algae-derived DOM secreted in algal exudates; F algal-bacterial co-culturability assessment to study different types of symbiotic associations viz. antagonism, mutualism, or no interaction between the two organisms, and $\mathbf{G}$ identification of algal-bacterial model consortium based on the active exchange of iron and DOM. 

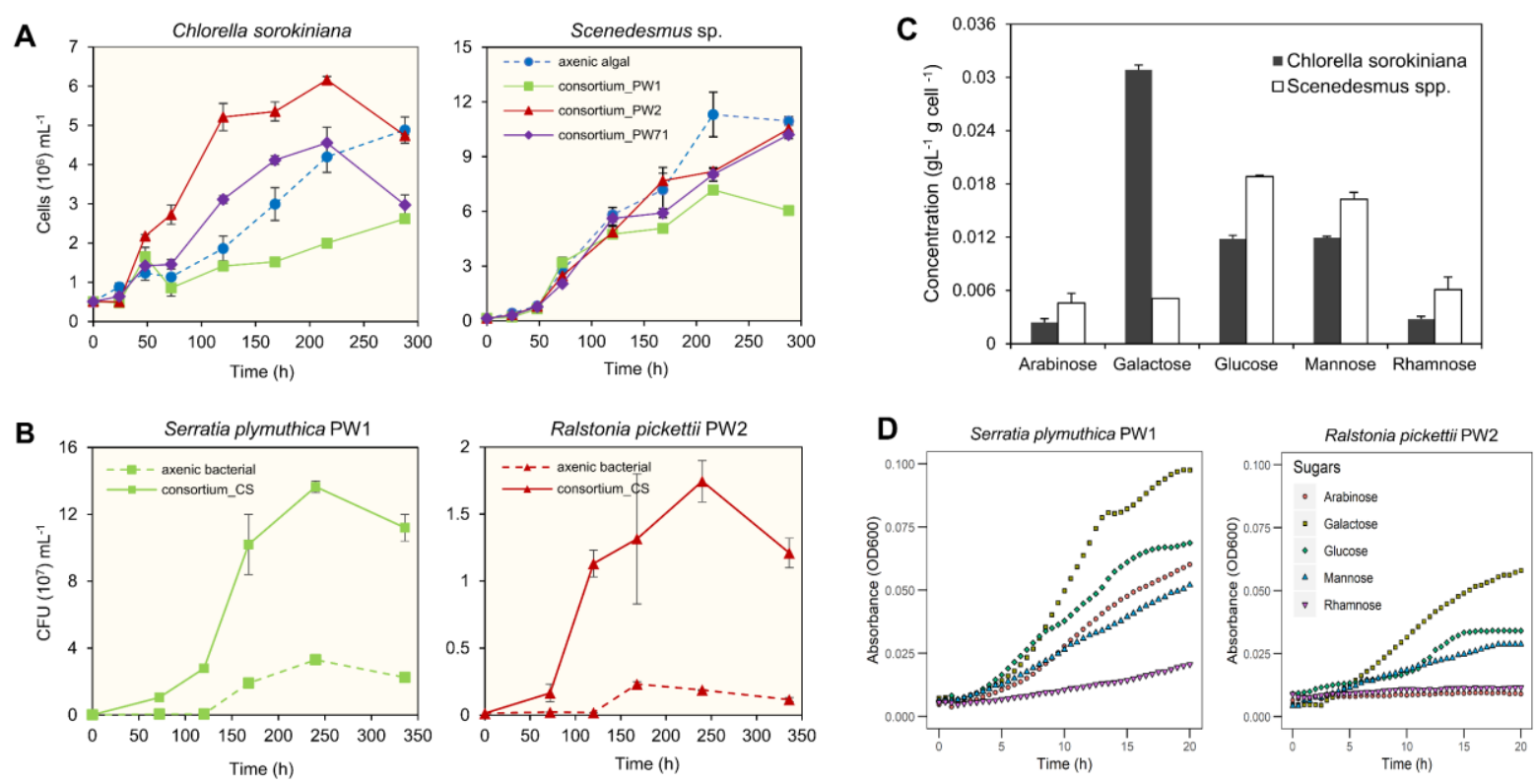

Fig. 2 Assessment of algal and bacterial growth in co-culture experiments. A Algal cell counts from co-culture experiments suggesting mutualistic effect of Ralstonia pickettii PW2 on C. sorokiniana. Serratia plymuthica PW1 on the other hand showed antagonistic effect on $C$. sorokiniana, and Serratia liquefaciens PW71 showed neutral effect. The effect of bacteria on growth of Scenedesmus sp. in co-culture was less prominent. B The assessment of the CFUs of bacterial strains in algal-bacterial co-culture suggest the growth promoting effect of Chlorella sorokiniana on PW1 and PW2. C Anion-exchange chromatography suggests a difference in the glycosyl composition in the EPS content of two freshwater microalgae. D The bacterium Serratia plymuthica PW1 also showed high culturability in all 5 sugars suggesting the generalist behavior of the strain. Whereas, bacterium Ralstonia pickettii PW2 showed limited culturability only in galactose followed by glucose and mannose. Galactose was preferred by both the bacteria. 

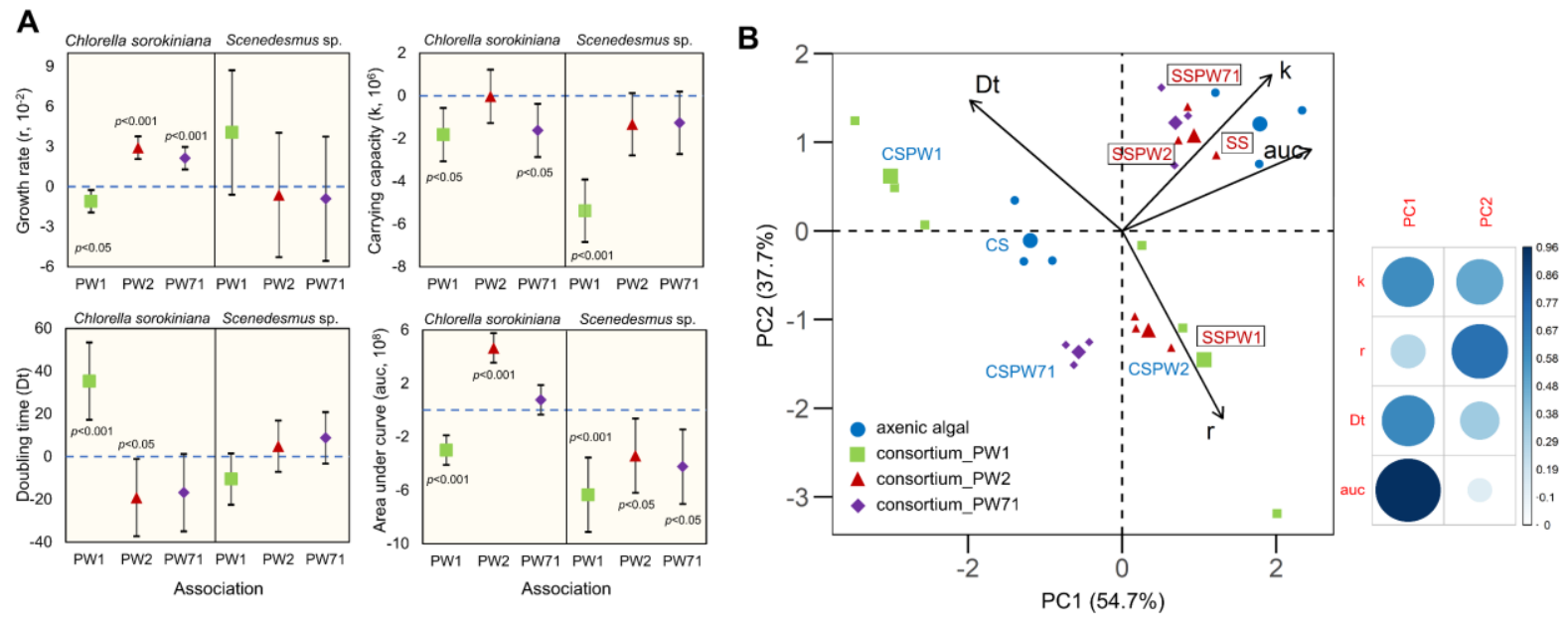

Fig. 3 Assessment of algal growth parameters in algal-bacterial consortium under iron-

limiting conditions. A Confidence interval plots of various algal growth parameters in consortium with respect to axenic growth (horizontal blue dashed line). Under iron stress, Ralstonia pickettii PW2 significantly increased growth rate (r) and area under curve (auc) of $C$. sorokiniana w.r.t. axenic culture. On the contrary, bacterium Serratia plymuthica PW1 showed significant reduction in growth rate, carrying capacity, and area under curve matrices of Chlorella. B PCA biplot of C. sorokiniana in consortium with PW1, PW2 and PW71 examining growth rate (r), doubling time (Dt) carrying capacity $(\mathrm{k})$ and area under curve (auc). The biplot separates the Chlorella sorokiniana in consortium (consortium_PW2) from axenic algal setup on the basis of growth rate (r). Whereas, bacterium Serratia plymuthica PW1 increased the doubling time of the algae (consortium_PW1). The growth of algae Scenedesmus (SS), on the other hand, was not significantly different when co-cultured with all bacterial strains except for Serratia plymuthica PW1. 

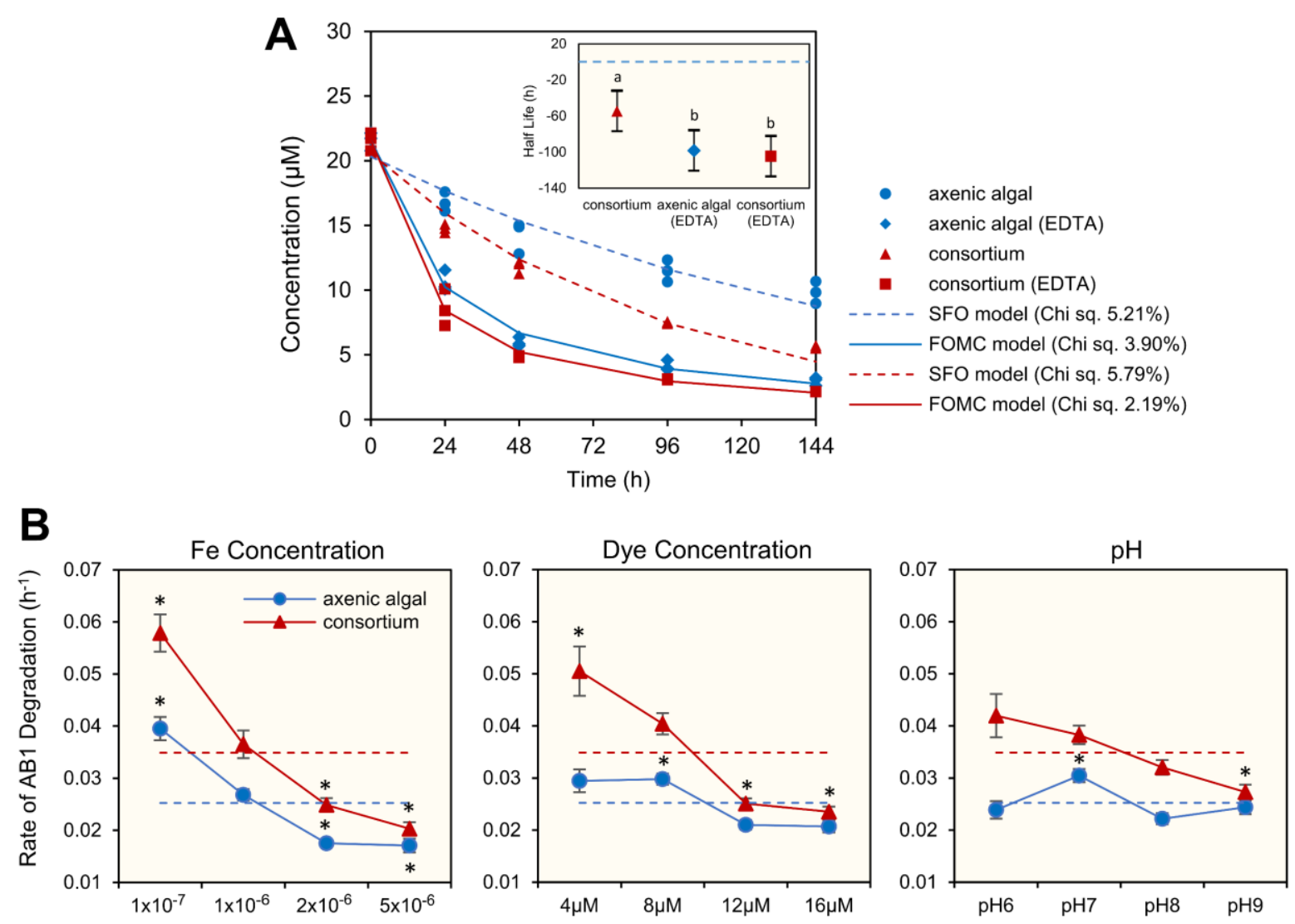

Fig. 4 Dye degradation assessment of algal-bacterial consortium. A Degradation of Acid Black 1 (AB1) textile dye followed a Single First Order (SFO) kinetics without EDTA and biphasic First Order Multi-compartment (FOMC) with EDTA. Concentration of AB1 after incubation with $C$. sorokiniana in axenic and consortia set ups. Inset; blue horizontal dashed line represents half-life in axenic algal setup without EDTA supplemented iron. Comparison of half-life with respect to culture without EDTA supplementation is denoted by ' $a$ ' and ' $b$ ' grouping after Tukey's post hoc test. B Analysis of Taguchi's orthogonal array using a multiple linear regression model to investigate the impact of iron concentration, dye concentration and $\mathrm{pH}$ on $\mathrm{AB} 1$ degradation. Concentration of iron has the highest effect on the rate of $\mathrm{AB} 1$ degradation followed by dye concentrations. The '*' symbol represents the significant difference of the means from the coefficient (dashed line; Supplementary Table S7). 

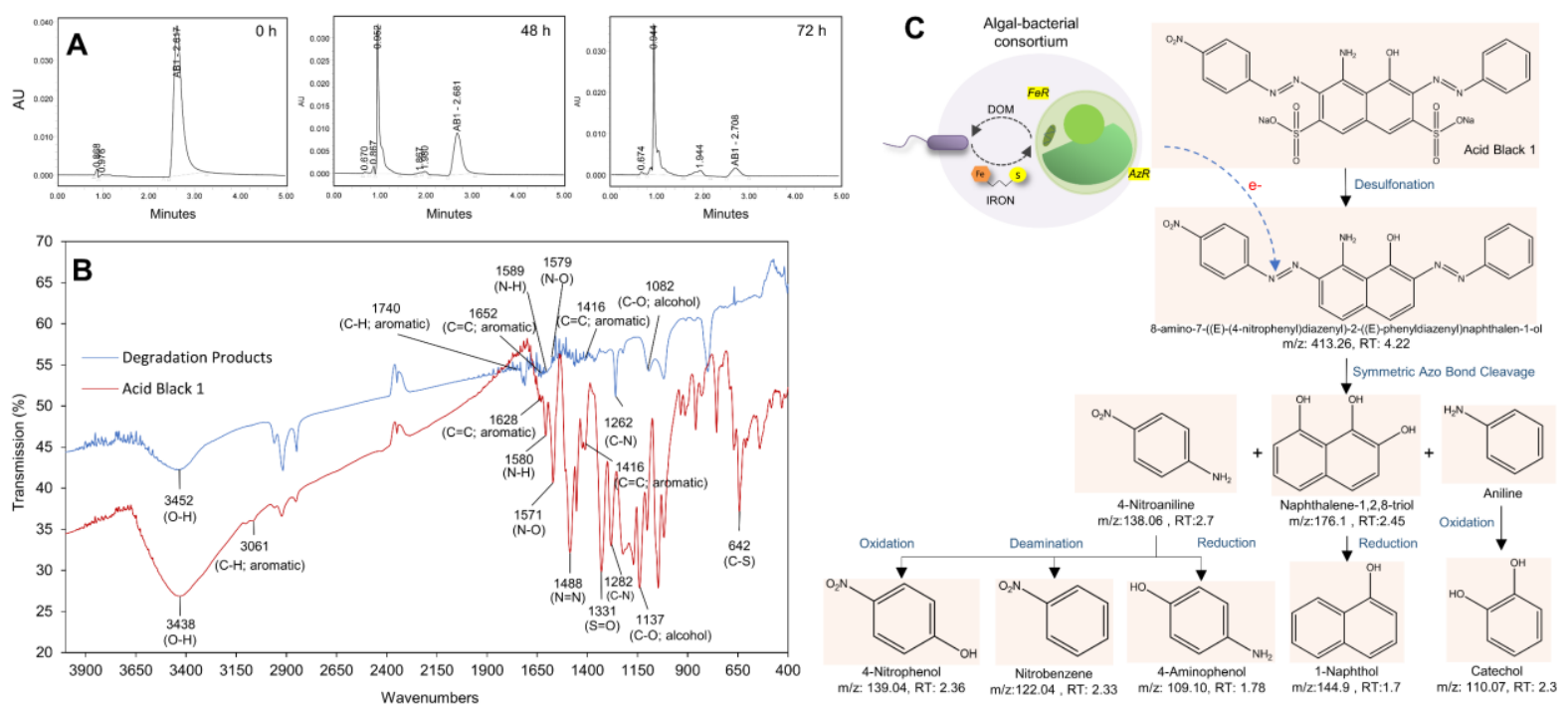

Fig. 5 Analysis of AB1 degradation products. A UPLC analysis suggests the disappearance of the peak (RT 2.617) of Acid Black 1 (AB1) dye after treatment with algal-bacterial consortium. B The FT-IR spectra of Acid Black 1 dye and its degradation products after microbial treatment suggests the difference in the functional groups. C LCMS analysis of degradation products, and a suggested microbe-mediated biodegradation pathway of $\mathrm{AB} 1$ represents the azoreductase-mediated symmetrical cleavage of azo bond. 

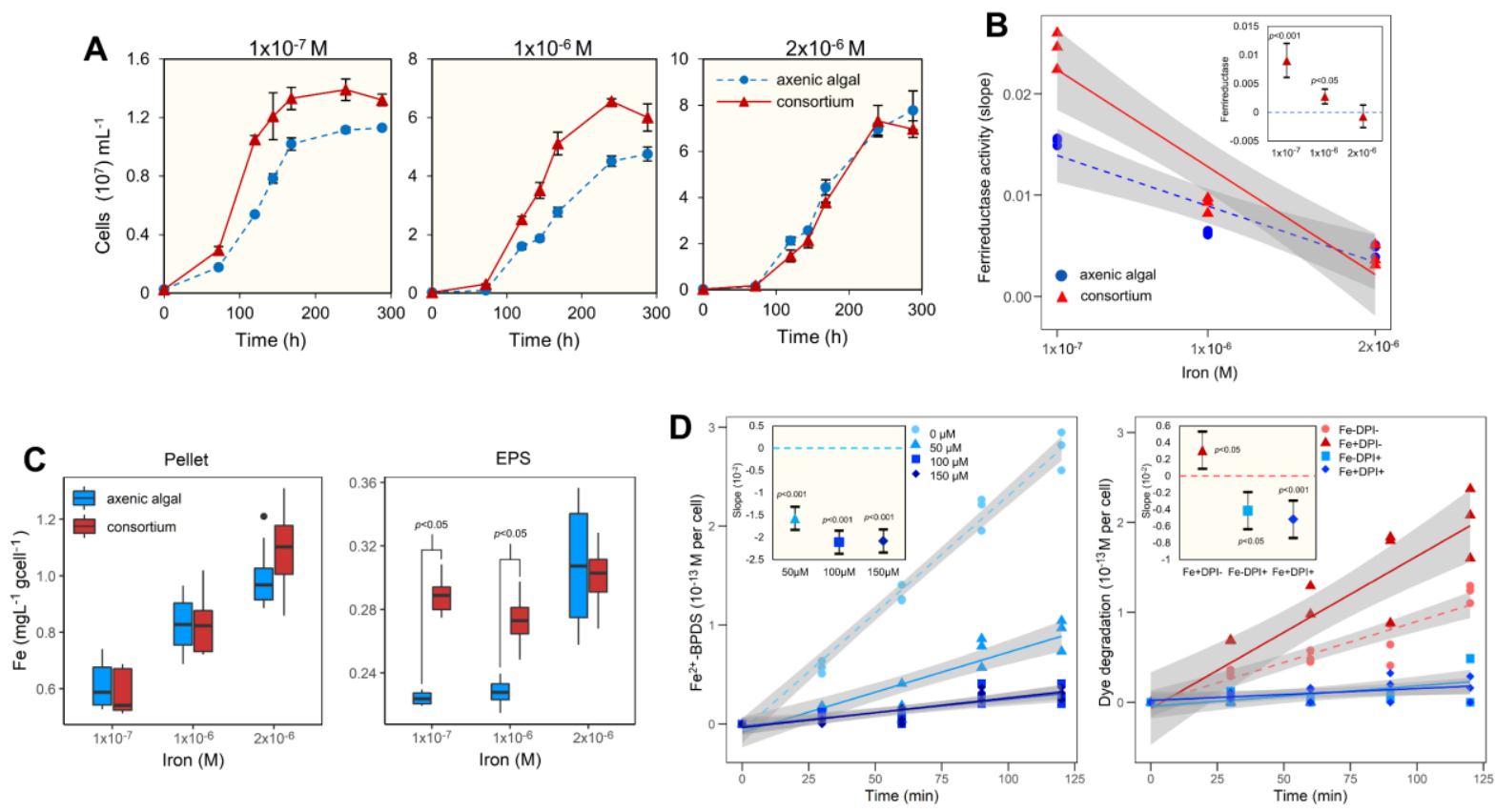

Fig. 6 Impact of iron concentration on the growth and enzyme activity of $C$. sorokiniana.

A Cell counts from algal-bacterial co-culture under three different iron concentrations. B Assay of extracellular ferrireductase activity of algae under different iron concentrations suggests bacteria-mediated significant increase in enzyme at lower Fe concentration (inset; confidence interval plot). C ICP-MS analysis of iron concentration in cell pellet and EPS under different iron concentrations. Algae accumulate more iron within EPS in presence of bacteria $(t$-test, $p<0.05)$. D Ferrireductase assay conducted in the presence of Diphenyleiodonium (DPI) to assess extracellular iron-reductive pathway and azoreductase assay to assess azo dye degradation in Chlorella sorokiniana. Here, Fe-DPI-, Fe+DPI-, Fe-DPI+, and Fe+DPI+ represents different treatment setups and '+' and '-' denotes presence and absence. Pre-treatment of algal cells with $50 \mu \mathrm{M}$ DPI significantly reduced extracellular ferrireductase activity and azoreductase activity. 


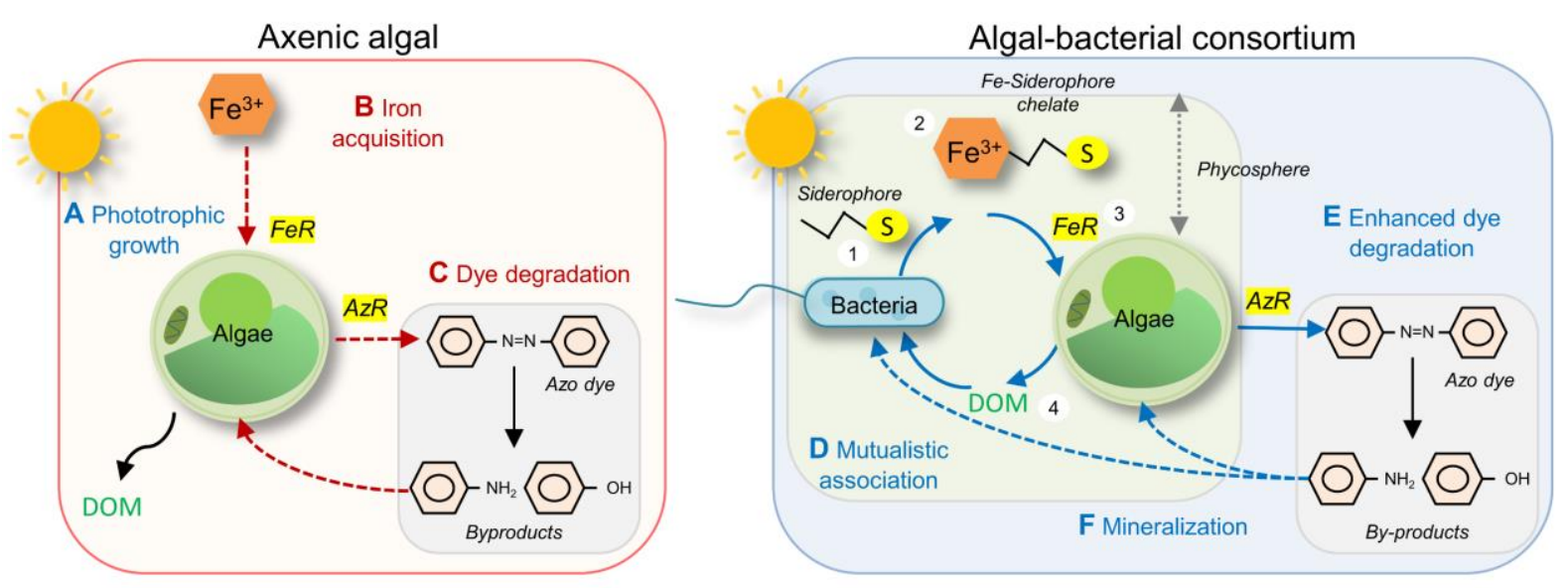

Fig. 7 Proposed advantages of working with an algal-bacterial consortium in comparison to axenic algal treatment setups for remediation of dyes. A In a phototrophic textile wastewater treatment setup, $\mathbf{B}$ algae have to perform multiple tasks like iron acquisition, and $\mathbf{C}$ extracellular degradation of toxic dyes which leads to metabolic burden (dashed red lines) and affects algal growth. Algae has a poor iron uptake mechanism, however, a consortium between algae and siderophore producing bacteria, will increase the bioavailability of iron for algae and reduce the metabolic burden (blue solid lines). D The mutualistic association between algae and bacteria takes place in the algal phycosphere (aquatic analogous of rhizosphere) which allows the exchange of micronutrients like iron, vitamins, Dissolved Organic Matter (DOM) [19]. The bacterial-secreted siderophores chelates non-bioavailable $\mathrm{Fe}^{3+}$ and increased the iron bioavailability for ferrireductase (FeR) mediated uptake (steps 1 to 3 in figure). Under iron limiting conditions, the siderophore-mediated increase in iron bioavailability also increases ferrireductase activity, and thereby, algal growth. Iron is an important macronutrient required for growth, enzymatic reactions, photosynthesis, and nitrate reduction in algae. Algae, on the other hand provides DOM for sustenance of bacteria (step 4) [21]. E From the study on Chlorella sorokiniana and Ralstonia pickettii PW2, the increase in bioavailability of iron also influenced the extracellular azoreductase (AzR) mechanism. The experimental evidence from this study suggests that the bacteria enhanced the algal ferrireductase and azoreductase activity, thus highlighting the potential link between these two enzymes [75]. F Therefore, a consortium can decolorize the dye and further mineralize the degradation products. The microbial consortium with autotrophic algae and heterotrophic bacteria will require minimum input for growth and will provide a sustainable bioremediation strategy. 
Table 1: Characterization of siderophore production in bacterial strains isolated from textile wastewater.

\begin{tabular}{|c|c|c|c|}
\hline \multirow[t]{2}{*}{ Bacteria } & \multicolumn{3}{|c|}{ Concentration $\left(\mu \mathrm{M} \mathrm{mL}^{-1}\right)$} \\
\hline & $\begin{array}{l}\text { Universal-CAS } \\
\text { assay (w.r.t. } \\
\text { Desferrioxamine } \\
\text { mesylate) }\end{array}$ & $\begin{array}{l}\text { Catecholate- } \\
\text { Arnow's assay } \\
\text { (w.r.t. 2'3- } \\
\text { Dihydroxybenzoic } \\
\text { acid) }\end{array}$ & $\begin{array}{l}\text { Hydroxamate- } \\
\text { Csaky's assay (w.r.t. } \\
\text { Desferrioxamine } \\
\text { mesylate) }\end{array}$ \\
\hline Serratia plymuthica PW1 & $15.26 \pm 1.28$ & $81.10 \pm 9.85$ & $1.35 \pm 1.03$ \\
\hline Ralstonia pickettii PW2 & $10.85 \pm 0.70$ & $97.43 \pm 16.86$ & NA \\
\hline \multicolumn{4}{|l|}{ Stenotrophomonas } \\
\hline rhizophila PW3 & $1.31 \pm 0.40$ & NA & NA \\
\hline \multicolumn{4}{|l|}{ Stenotrophomonas } \\
\hline maltophilia PW5 & $1.28 \pm 0.34$ & $2.77 \pm 1.20$ & $37.86 \pm 0.46$ \\
\hline \multicolumn{4}{|l|}{ Stenotrophomonas } \\
\hline maltophilia PW6 & $1.63 \pm 0.07$ & $2.43 \pm 0.33$ & $17.73 \pm 0.26$ \\
\hline \multicolumn{4}{|l|}{ Serratia liquefaciens } \\
\hline PW71 & $13.28 \pm 0.92$ & $103.1 \pm 8.33$ & NA \\
\hline \multicolumn{4}{|l|}{ Stenotrophomonas } \\
\hline rhizophila PW72 & $0.91 \pm 0.63$ & $7.4 \pm 6.86$ & NA \\
\hline
\end{tabular}

